

\section{Sumário}

Dossiê TEMÁTICO: NOVOS INSTITUTOS JURÍDICOS DE LICITAÇÕES E CONTRATOS 17

I. LicitaÇõEs E CONTRATOS PÚBLICOS: PARTE GERAL. 18

INTEGRATED CONTRACT IN LAW 14.133/2021: NEW LAW, SAME PROBLEMS? A STUDY OF COMPARATIVE LAW .20

Paulo Afonso Cavichioli Carmona, Bruno Ribeiro Marques e Odilon Cavallari

Reajustamento de preços na Nova Lei de Licitações e Contratos Administrativos BRASILEIRA: O "Princípio" Da ANUALIDAde.

Ricardo Silveira Ribeiro e Bráulio Gomes Mendes Diniz

A nova Lei de Licitações, as encomendas tecnológicas e o diálogo competitivo .61 André Dias Fernandes e Débora de Oliveira Coutinho

LiCITAÇÕES, CONTRATOS E O IMPULSO À APRENDIZAGEM PROFISSIONAL: UM ESTUDO SOBRE A CONTRATAÇÃo de APRENDizes no ESTAdo do AMAZONAS, BRAsIL

Emerson Victor Hugo Costa de Sá, Natasha Yasmine Castelo Branco Donadon e Mauro Augusto Ponce de Leão Braga

Licitações, contratos e Modelo Brasileiro de Processo: notas sobre a viabilidade DA UTILIZAÇÃo DE FERRAMENTAS PROCESSUAIS PARA CONFERIR MAIOR EFICIÊNCIA ÀS AQUISIÇÕES PÚBLICAS

Claudio Madureira e Carlos André Luís Araujo

RESOlUÇão DE CONFLITOS COM A ADMINISTRAÇÃo PÚBLICA E A NOVA LEI DE LICITAÇÕES E CONTRATOS: REFORÇO DOS MEIOS ALTERNATIVOS.

Clarissa Sampaio Silva e Danille Maia Cruz

A Adesão do Brasil ao Acordo sobre Contratações Públicas da OMC: entre tabus e DIFICULDADES REAIS

Eduardo Ferreira Jordã e Luiz Filippe Esteves Cunha

II. Accountability e controle

A LEI N. ${ }^{\circ}$ 14.133/2021 E OS NOVOS LIMITES do CONTROLE EXTERNO: A NECESSÁRIA DEFERÊNCIA dos Tribunais de Contas em prol da Administração Pública .................................. 162 Ricardo Schneider Rodrigues

O CONTROLE DAS CONTRATAÇÕES PÚBliCAS E A NOVA LEI DE LICITAÇÕES: O QUE HÁ DE Novo? 183

Leandro Sarai, Flávio Garcia Cabral e Cristiane Rodrigues Iwakura 
Programa de compliance como exigênCia em licitações: ANálises EM Prol da QUALIFICAÇÃo DO PROCESSO LICITATÓRIO NO CONTEXTO DA LEI 14.133/2021.

Cristian Ricardo Wittmann e Anayara Fantinel Pedroso

A NOVA REALIDAde bRASILEIRA DE NECESSIDADE DE PROGRAMAS DE INTEGRIDADE DAS PESSOAS JURÍDICAS LICITANTES EM PROCESSOS LICITATÓRIOS DA ADMINISTRAÇÃO PÚBLICA 227

Fernando Silva Moreira dos Santos e Luiz Fernando de Oriani e Paulillo

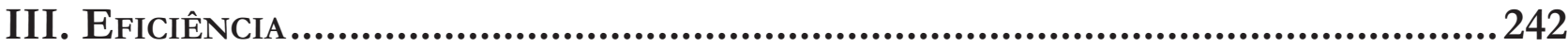

Efficiency contracts in the New Brazilian Procurement Law: conceptual FRAMEWORK AND INTERNATIONAL EXPERIENCE

Floriano de Azevedo Marques Neto, Hendrick Pinheiro e Tamara Cukiert

A gestão de riscos como instrumento para a aplicação efetiva do Princípio Constitucional dA EFICIÊNCIA.

Rafael Rabelo Nunes, Marcela Teixeira Batista Sidrim Perini e Inácio Emiliano Melo Mourão Pinto

IV. Contratação PÚblica No Direito ESTrangeiro

LA ADQUisición de VACUNAS CONTRA LA COVID-19 POR COLOMBIA: ENTRE LA CONFIDENCIALIDAD Y LA FALTA DE TRANSPARENCIA. 284

Gressy Kareny Rojas Cardona e David Mendieta

LA DISCRIMINACIÓN EX POST DE LOS OFERENTES DE UNA LICITACIÓN PÚBLICA COMO INFRACCIÓN ADMINISTRATIVA Y DE LIBRE COMPETÊNCIA 312 Jaime Arancibia Mattar

LA DISCRIMINACIÓN EX POST DE LOS OFERENTES DE UNA LICITACIÓN PÚBLICA COMO INFRACCIÓN ADMINISTRATIVA Y DE LIBRE COMPETÊNCIA..........................................................332 Udochukwu Uneke Alo, Obiamaka Adaeze Nwobu e Alex Adegboye

Outros Temas 348

I. Políticas públicas e institucionalidade

¿Existe El derecho humano a la identidad Cultural de los Migrantes en El Derecho INTERNACIONAL? 351 Juan Jorge Faundes e Glorimar Alejandra Leon Silva

El acceso a la justicia y el debido proceso ante el Tribunal Constitucional y la CorTe Suprema: dos NOCIONES DEL CONTENCIOSO ADMINISTRATIVO CHILENO .384 Pedro Harris Moya 
“Ministrocracia” E DECISÕES INDIVIDUAis CONTRAditórias No Supremo Tribunal FEDERAI

Ulisses Levy Silvério dos Reis e Emilio Peluso Neder Meyer

A POlÍtica de INOVAÇÃo COMO INSTRUMENTO DE REDUÇÃo DAS DESIGUALDADES REGIONAIS NO BRASIL

Caroline Viriato Memória e Uinie Caminha

Conflitos de Competência E A JudicializaÇão da Saúde no Federalismo Brasileiro.447 Jorge Leal Hanai, Luis Antônio Abrantes e Luiz Ismael Pereira

O Ministério Público no enfrentamento dos Reflexos da CRise da Covid-19: UMA

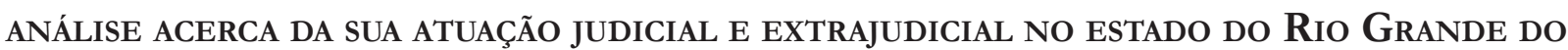
NorTE

Raquel Maria da Costa Silveira, Ana Mônica Medeiros Ferreira, Flávio Luiz Carneiro Cavalcanti e Haroldo Helinski Holanda

A CONSAgRaÇão CONSTITUCIONAL DA POlítica FALIMENTAR

Nuno de Oliveira Fernandes

II. Políticas públicas, grupos vulneráveis e litígios estruturais

LAS LIMITACIONES A LOS DERECHOS DE LOS GRUPOS VULNERABLES Y LOS SUJETOS DE ESPECIAL PROTECCIÓN DURANTE LA PANDEMIA Mary Luz Tobón Tobón

LitígIOS ESTRUTURAIS E A PROTEÇÃO DOS DIREITOS DOS POVOS INDÍGENAS DURANTE A PANDEMIA DE Covid-19: CONTRIBUições do ICCAL

Ana Carolina Lopes Olsen e Bianca M. Schneider van der Broocke

EPISTEMICÍDIO DAS NARRATIVAS NEGRAS E LITÍGIO ESTRUTURAL: INSTRUMENTOS EXTRAJUDICIAIS PARA DISSOLUÇÃO DO PROBLEMA NO SISTEMA EDUCACIONAL .......................................582

Vitor Fonsêca e Caroline da Silva Soares

Trajetórias E DiRETRIZES dAS POlíticas PÚbliCAS NACIONAIS PARA A POPULAÇão INFANTOJUVENIL EM SITUAÇÃO DE RUA...

Wânia Cláudia Gomes Di Lorenzo Lima, Cynthia Xavier de Carvalho e Maria Creusa de A. Borges

Emprendimiento como Fuente de Ingresos para las Víctimas del Conflicto Armado en el Marco de la Ley 1448 de Colombia. Reflexiones de la Implementación en el Valle del Cauca

Saulo Bravo García e Luz Marina Restrepo García

III. Políticas públicas e aÇão Restaurativa. 
JUSTIÇA RESTAURATIVA COMO AÇÃO COMUNICATIVA: EQUILÍBRIO ENTRE SISTEMA E MUNDO DA

Daniela Carvalho Almeida da Costa e Luciana Leonardo Ribeiro Silva de Araújo

JUSTIÇA RESTAURATIVA: ACORDOS E COOPERAÇÃO.................................................668

Samyle Regina Matos Oliveira e Selma Pereira de Santana 


\title{
O Ministério Público no enfrentamento dos reflexos da crise da covid-19: uma análise acerca da sua atuação judicial e extrajudicial no estado do Rio Grande do Norte*
}

\author{
The public prosecution's office in facing the \\ reflections of the covid-19 crisis: an analysis \\ about its judicial and extrajudicial action in the \\ state of Rio Grande do Norte
}

\author{
Raquel Maria da Costa Silveira** \\ Ana Mônica Medeiros Ferreira*** \\ Flávio Luiz Carneiro Cavalcanti**** \\ Haroldo Helinski Holanda*****
}

* Recebido em 23/04/2021

Aprovado em 02/08/2021

Todos os autores são pesquisadores do projeto "Controle Judicial de Políticas Públicas a partir dos reflexos da pandemia da Covid-19: o papel do Poder Judiciário na etapa da implementação" (UFRN).

** Docente do Departamento de Políticas Públicas, atuando na Graduação em Gestão de Políticas Públicas e no Programa de Pós-Graduação em Estudos Urbanos e Regionais (UFRN), Doutora em Ciências Sociais pela Universidade Federal do Rio Grande do Norte (UFRN), Pesquisadora do Observatório das Metrópoles (Núcleo Natal) e do Grupo de Pesquisa Estado e Políticas Públicas (UFRN).

E-mail: raquelmcsilveira@hotmail.com

*** Advogada. Professora do Curso de Graduação em Direito da Faculdade de Direito da Universidade do Estado do Rio Grande do Norte (UERN) e Pós-Graduação em Direito do Centro Universitário do Rio Grande do Norte (UNIRN). Doutora em Ciências Sociais pela Universidade Federal do Rio Grande do Norte (UFRN). Doutoranda em Direito Público pela Faculdade de Direito da Universidade do Porto, Portugal (FDUP). Pesquisadora do Observatório das Metrópoles (Núcleo Natal) e do Grupo de Pesquisa Estado e Políticas Públicas (UFRN).

E-mail: anamonicamf@gmail.com

**** Bacharel em Direito (UnP) e graduando em Gestão de Políticas Públicas (UFRN).

E-mail: flavio.carneiro.010@ufrn.edu.br

***** Bacharel em Ciências Contábeis (UnP) e graduando em Gestão de Políticas Públicas (UFRN).

E-mail: haroldohh@gmail.com

\section{Resumo}

O presente estudo objetivou compreender a atuação do Ministério Público do Estado do Rio Grande do Norte a respeito do contexto da pandemia da COVID-19 entre março e setembro de 2020. Para tanto, foi realizado o levantamento das atividades do Parquet com base no portal de notícias do MPRN, considerando-se, na análise, o período de atuação; a classificação da medida; o tema; o recorte territorial da atuação; atores envolvidos e a etapa da política pública de cada medida analisada. Em seguida, classificaram-se as atividades do MPRN com base nas tipologias apontadas em Goulart ${ }^{1}$; Coelho e Kozicki ${ }^{2}$; Silva ${ }^{3}$ e Da Ros ${ }^{4}$. Os resultados obtidos evidenciaram, de um lado, a preferência pelo diálogo a respeito das políticas públicas e da atuação extrajudicial em um contexto de crise sanitária e, de outro, a existência de conflitos internos que explicitaram a discricionariedade que caracteriza a atuação do Ministério Público no Brasil. Vale ressaltar que os dados se referem à atuação noticiada pelo pela própria instituição, não abrangendo a totalidade do esforço realizado pelo MPRN no período da pesquisa.

Palavras-chave: Ministério Público; Atuação extrajudicial; Políticas públicas; Discricionariedade; COVID-19.

GOULART, Marcelo Pedroso. Ministério Público e democracia: teoria e práxis. São Paulo: Led Editora de Direito, 1998.

${ }^{2}$ COELHO, Sérgio Reis; KOZICKI, Katya. O Ministério Público e as políticas públicas: definindo a agenda ou implementando as soluções? Revista da AJURIS, Porto Alegre, v. 40, n. 130, p. 373-394, jun. 2013.

3 SILVA, Cátia Aida. Promotores de justiça e novas formas de atuação em defesa de interesses sociais e coletivos. Revista Brasileira de Ciências Sociais, São Paulo, v. 16, n. 45, p. 127-144, fev. 2001.

${ }^{4}$ DA ROS, Luciano. Ministério público e sociedade civil no Brasil contemporâneo: em busca de um padrão de interação. Revista Política Hoje, Recife, v. 18, n. 1, 2009. 


\section{Abstract}

This study aimed to understand the role of the Public Prosecutor's Office of the State of Rio Grande do Norte in the context of the COVID-19 pandemic between March and September 2020. Therefore, a survey of Parquet activities was carried out based on the portal of MPRN news, considering, in the analysis, the period of operation; the classification of the measure; the theme; the territorial cut of the performance; involved actors and the stage of public policy of each measure analyzed. Then, the activities of the MPRN were classified based on the typologies pointed out by Goulart; Coelho and Kozicki; Silva and Da Ros. The results obtained evidenced, on the one hand, the preference for dialogue regarding public policies and extrajudicial action in a context of sanitary crisis and, on the other, the existence of internal conflicts that explained the discretion that characterizes the performance of the Public Ministry in the Brazil. It is noteworthy that the data refer to the performance reported by the institution itself, not covering the entire effort made by the MPRN during the research period.

Keywords: Public Prosecutor's Office; Extrajudicial performance; Public policy; Discretion; COVID-19.

\section{Introdução}

A pandemia do coronavírus provocou crises e exacerbou desigualdades no Rio Grande do Norte. Além dos milhares de casos e das mortes provocadas pelo vírus, a necessidade de adoção de medidas restritivas provocou conflitos políticos e sociais no estado.

Nesse contexto, foi marcante a atuação realizada pelo Ministério Público estadual, sendo recorrentemente reportada a participação de um de seus representantes em reuniões com o Executivo estadual, ou, ainda, a realização de parcerias com outros atores. Foi intenso o diálogo realizado entre o Governo Estadual, Municípios, universidades, comitês científicos, setor produtivo, sociedade civil e Ministério Público do Estado do Rio Grande do Norte (MPRN). Contudo, as discordâncias entre os entes públicos e destes com atores privados também se mostraram evidentes. Mas, como se caracteriza a atuação do MPRN durante a crise? A massiva atuação representou, necessariamente, um extrapolamento das suas atribuições legais?

Nesse sentido, esta investigação objetivou compreender o perfil de atuação do Ministério Público do Estado do Rio Grande do Norte no contexto da pandemia da covid-19 entre março e setembro de 2020.

O recorte temporal da pesquisa foi definido com base na observância do primeiro pico de casos no estado. O Rio Grande do Norte ( $\mathrm{RN}$ ) apresentou uma primeira onda de casos de março a setembro, com novo aumento entre os meses de outubro e novembro ${ }^{5}$. Assim, foi considerado o referido recorte temporal, que abrangeu os primeiros registros de aumento e a primeira queda do número de casos no estado, observando-se o agravamento da pandemia em junho e julho de 2020.

Para fins de coleta de dados, realizou-se o levantamento das atividades do Parquet com base no portal de notícias do MPRN, considerando-se, na análise, o período de atuação; a classificação da medida; o tema; o recorte territorial da atuação; atores envolvidos e a etapa da política pública à qual se referiu a medida. Em seguida, foi possível classificar as atividades do MPRN com base nas tipologias apontadas inicialmente por Marcelo Pedroso Goulart ${ }^{6}$ e após por Sérgio Reis Coelho e Katya Kozicki: Ministério Público demandista

\footnotetext{
5 VALENTIM, Ricardo et al. (org.). Rio Grande do Norte: uma análise da epidemia da covid-19: análise da evolução da epidemia da covid-19 no estado do RN à luz da ciência de dados na saúde. 2020. Disponível em: https://covid.lais.ufrn.br/publicacoes/Relatorio_covid-19-LAIS_UFRN_20201219.pdf Acesso em: 24 fev. 2021.

${ }^{6}$ GOULART, Marcelo Pedroso. Ministério Público e democracia: teoria e práxis. São Paulo: Led Editora de Direito, 1998.

7 COELHO, Sérgio Reis; KOZICKI, Katya. O Ministério Público e as políticas públicas: definindo a agenda ou implementando as soluções? Revista da AJURIS, Porto Alegre, v. 40, n. 130, p. 373-394, jun. 2013.
} 
e Ministério Público resolutivo; Cátia Silva ${ }^{8}$ Promotores de gabinete e Promotores de fatos e Luciano Da Ros?: Órgão tutelar; órgão de mediação e órgão protetor.

O artigo discute a expansão da função juspolítica protagonizada pelo Ministério Público com base no marco teórico mencionado, em decorrência da recente projeção da atuação judicial e extrajudicial da instituição no contexto da pandemia da COVID-19 com base na função exercida por Promotores e Procuradores de Justiça no Estado do Rio Grande do Norte. Trata-se de pesquisa que faz uso de raciocínio analítico, valendo-se de dados de natureza secundária, permitindo concluir que, para evitar o arbítrio e, consequentemente, desequilíbrios políticos e sociais, o Ministério Público adota um perfil institucional que potencializa a sua atuação, com foco na preparação para o exercício eficiente da condição de defensor do interesse público.

O presente artigo organiza-se, além desta introdução e das considerações finais, em três partes. Na primeira, será discutida a institucionalização da defesa do interesse público com base no papel do Ministério Público no Brasil. Em seguida, serão exploradas as características da atuação do MP e a sua relação com a discricionariedade, relacionando-se tais elementos com o contexto da pandemia da COVID-19. Por fim, serão apresentados os resultados da pesquisa realizada, possibilitando a análise da atuação do MPRN durante a crise sanitária.

\section{A institucionalização da defesa do interesse público: o papel do Ministério Público no Brasil}

O processo de redemocratização, no qual a elaboração da Constituição Federal de 1988 (CF88) foi inspirada, fez emergir o Ministério Público como uma instituição de grande prestígio na sociedade brasileira. Nos termos da carta cidadã, o órgão teve sua atuação ampliada para constituir-se como o meio mais eficiente de defesa do próprio regime democrático que se irrompia, para aplicação das leis e cumprimento dos direitos coletivos. Nesse sentido, o Ministério Público se notabilizou na luta pelos direitos dos cidadãos.

Antes da atual Constituição, incumbia ao Ministério Público o exercício de dupla função, representando judicialmente tanto o Estado quanto o interesse público, além de ser acusador na persecução penal ${ }^{10}$. Os incrementos em suas prerrogativas implicaram um processo de deslocamento constitucional e legal de suas funções em direção à defesa dos interesses de segmentos importantes da sociedade civil.

Sem dúvidas, trata-se de um novo perfil institucional atribuído nos termos dos artigos 127 e 129, da CF88, que lhe incumbem a defesa da ordem jurídica, do regime democrático e dos interesses sociais e individuais indisponíveis, promovendo a aplicação e a execução das leis. Portanto, as atribuições transbordam para além da responsabilidade pela ação penal pública junto aos tribunais.

Cabe, então, ao Ministério Público investigar e denunciar os atos contrários ao interesse público, na função de promotores e garantidores da cidadania. Nesse propósito de servir à sociedade e defender a coletividade, possui importante papel em prol da inclusão social.

Esse processo se dá em detrimento de atividades tradicionais, como órgão essencial à Justiça. Como dito por Abreu"11 "o Ministério Público deve ser o braço da inclusão do cidadão, atender mais ao público e buscar seu esforço distante do Poder Judiciário, sobremaneira moroso e lucrativo". Diante disso, exige-se mais

\footnotetext{
8 SILVA, Cátia Aida. Promotores de justiça e novas formas de atuação em defesa de interesses sociais e coletivos. Revista Brasileira de Ciências Sociais, São Paulo, v. 16, n. 45, p. 127-144, fev. 2001.

9 DA ROS, Luciano. Ministério público e sociedade civil no Brasil contemporâneo: em busca de um padrão de interação. Revista Política Hoje, Recife, v. 18, n. 1, 2009.

${ }^{10}$ DA ROS, Luciano. Ministério público e sociedade civil no Brasil contemporâneo: em busca de um padrão de interação. Revista Politica Hoje, Recife, v. 18, n. 1, 2009.

11 ABREU, Alzira Alves de. O que é o Ministério Público? Rio de Janeiro: FGV, 2010. p.73.
} 
eficácia social de sua atuação em função da existência da grande demanda reprimida de ações não resolvidas pelo Poder Judiciário ${ }^{12}$.

Processualmente, a previsão da Ação Civil Pública por força da Lei n. ${ }^{\circ} 7.347 / 85$ agregou novas matérias passíveis da tutela judicial do Ministério Público, ampliando sobremaneira o raio de ação do órgão e finalmente colocando-o em contato direto com a representação judicial dos interesses de amplos segmentos da sociedade ${ }^{13}$.

O valor e a missão do Ministério Público se vinculavam à sua capacidade de intervenção judicial, notadamente na função de custos legis ou de persecução criminal ${ }^{14}$. Marcadamente após a promulgação da CF88, consolidou-se, então, um novo perfil institucional, assumindo relevantes funções na redefinição de seu papel perante a sociedade e o próprio sistema de justiça, compreendidas no eixo expansionista da noção de cidadania. Esse movimento demanda o reconhecimento de novos direitos e o aumento contínuo de reivindicações postas ao poder público, especialmente sobre a execução de políticas públicas. É percebido, então, um novo instrumento de concretização do interesse público.

Enquanto instituição autônoma e permanente projetada para a defesa dos interesses sociais e indisponíveis do Estado Democrático de Direito, o Ministério Público teve o rol de suas atribuições alargado, como também foi necessária a implementação de mecanismos de composição extrajudicial em sua atuação, consistindo em um foro privilegiado de resolução extrajudicial de conflitos que, via de regra, estavam na dependência da ação governamental e do Poder Judiciário para serem efetivados ${ }^{15}$.

Portanto, a CF88 trouxe atribuições ao Ministério Público por intermédio de seus Promotores e Procuradores; seja na área preventiva - enquanto tarefa de pacificação social e composição de conflitos - seja provocando a atuação jurisdicional, seja nela intervindo. Tanto numa das hipóteses como noutra, em todas suas atividades, o Ministério Público sempre deve atuar na defesa daquele interesse público primário, em busca de relevantes valores democráticos, em especial em busca do acesso do cidadão à prestação jurisdicional e à Justiça ${ }^{16}$.

Nesse novo cenário funcional, incluindo o papel de controle externo notadamente sobre o Poder Executivo, foi imprescindível a garantia de autonomia e independência funcional a seus membros frente a interesses políticos, e mesmo político-partidários, geralmente atrelados à defesa judicial dos interesses estatais.

Para Goulart ${ }^{17}$, o texto constitucional confere ao Ministério Público, portanto, uma missão de grande amplitude e relevância política, elevando a instituição ao patamar de co-construtor do projeto de democracia substantiva estabelecido pela CF88 exigindo uma atuação livre e independente para consolidação dos direitos sociais.

Essa mesma independência concedida pela Constituição Federal passa a ser alvo de críticas quando se expande para o exercício de suas funções politicamente engajadas. Compreendido como fenômeno de politização da justiça ou judicialização da política, aquele exercício abarca os efeitos da expansão de atuação dos órgãos do sistema de justiça no processo decisório das democracias contemporâneas ${ }^{18}$.

\footnotetext{
12 GORDILHO, Heron José de Santana; SILVA, Marco Antonio Chaves da. Avaliando o novo Ministério Público Resolutivo. Revista de Processo, Jurisdição e Efetividade da Justiça, Porto Alegre, v. 4, n. 2, p. 85-99, jul./dez. 2018.

13 DA ROS, Luciano. Ministério público e sociedade civil no Brasil contemporâneo: em busca de um padrão de interação. Revista Política Hoje, Recife, v. 18, n. 1, 2009.

${ }^{14}$ GORDILHO, Heron José de Santana; SILVA, Marco Antonio Chaves da. Avaliando o novo Ministério Público Resolutivo. Revista de Processo, Jurisdição e Efetividade da Justiça, Porto Alegre, v. 4, n. 2, p. 85-99, jul./dez. 2018.

15 GORDILHO, Heron José de Santana; SILVA, Marco Antonio Chaves da. Avaliando o novo Ministério Público Resolutivo. Revista de Processo, Jurisdição e Efetividade da Justiça, Porto Alegre, v. 4, n. 2, p. 85-99, jul./dez. 2018.

16 MAZZILLI, Hugo Nigro. O acesso à Justiça e o Ministério Público. 1989. Disponível em: http://mazzilli.com.br/pages/artigos/ acjusmp.pdf. Acesso em: 05 mar. 2021.

17 GOULART, Marcelo Pedroso. Ministério Público e democracia: teoria e práxis. São Paulo: Led Editora de Direito, 1998.

18 MACIEL, Débora Alves; KOERNER, Andrei. Sentidos da judicialização da política: duas análises. Lua Nova, São Paulo, n. 57, p. 113-133, 2002.
} 
Assim, o engajamento político teria alcançado os membros do Ministério Público que se valeriam, tradicionalmente, do contencioso judicial para a defesa dos direitos sociais, implicando no entendimento de que se prefere essa via para a solução de conflitos.

A atuação do Ministério Público, marcadamente na defesa de direitos sociais, se pautaria na combinação de percepções pessimistas: hipossuficiência da sociedade de se defender autonomamente e sobre os poderes político-representativos que estariam corrompidos e/ou incapazes de cumprir suas funções ${ }^{19}$.

Em um aspecto endógeno, diz-se que há idealização do papel político do Ministério Público. Essa percepção se revela na incumbência de o MP representar a sociedade entendida como incapaz perante governos ineptos, que não cumprem o enforcement da lei, muito embora aos membros do Parquet não sejam outorgado mandato explícito e não contem com mecanismos de accountability ${ }^{20}$.

Concomitante à crescente apropriação dos direitos de cidadania pela população, é verificado o desempenho de um papel de promotor de conscientização com vistas ao alargamento do acesso à justiça das demandas sociais, em especial as de natureza coletiva. Essa atuação denota que a institucionalização da democracia brasileira apresenta um déficit no seu modo de implementação. Isso resulta da predominância do Poder Executivo sobre o Legislativo e uma busca crescente de agentes sociais ao Poder Judiciário contra leis, práticas administrativas ou omissões tanto do Poder Executivo quanto do Legislativo ${ }^{21}$.

Independente e autônomo, mas não um quarto poder, o Ministério Público age em um complexo sistema de complementaridade e interdependência entre os poderes do Estado, a mídia, a sociedade civil organizada e os indivíduos ${ }^{22}$, redobrando sua relevância social como órgão constitucional considerado instituição permanente e essencial à função jurisdicional do Estado. Ademais, conforme estabelecido no texto constitucional, é previsto o monopólio institucional das funções do Ministério Público, que somente podem ser exercidas por integrantes da carreira.

Ainda nesse sentido, o Ministério Público goza de ampla autonomia funcional e administrativa. A instituição tem competência e legitimidade para propor ao respectivo Poder Legislativo a criação e extinção dos seus cargos e serviços auxiliares, provendo-os por concurso de provas ou de provas e títulos, a política remuneratória e os planos de carreira. Cumpre, ainda, ao próprio Ministério Público elaborar a sua proposta de orçamento dentro dos limites estabelecidos na lei de diretrizes orçamentárias (art. 169, CF88).

Dessa forma, a independência funcional se reflete na possibilidade de cada membro definir suas prioridades e criar seus métodos próprios de trabalho, a ponto de se defender a inexistência de subordinação hierárquica no âmbito do Ministério Público. Nesse caminho, operam vários fatores, como suas convicções, saberes acumulados nas diferentes áreas de especialização e experiências adquiridas durante a carreira. É dizer, portanto, que, na formação do ethos próprio da ação dos promotores de justiça, as diferentes formas de atuação refletem distintas formações, opiniões políticas e cargos ocupados ao longo da profissão ${ }^{23}$.

Ainda sobre a práxis ministerial, é relevante que se considere a sua autonomia, independência funcional e discricionariedade, constituindo-se esta como elemento primordial para a seleção e condução de casos concretos. A característica da discricionariedade afetaria sua atuação, refletindo-se, então, na garantia de direitos e nas políticas públicas, gerando consequências, inclusive, quanto ao próprio acesso à justiça. Isso porque o poder discricionário do membro do Parquet corresponde à permissividade de não investigar ou até mesmo processar, ceifando o encaminhamento de $\operatorname{casos}^{24}$.

\footnotetext{
19 ARANTES, Rogério Bastos. Ministério Público na fronteira entre a justiça e a política. Revista Justitia, São Paulo, v. 1, n. 197, p. 325-335, jul./dez. 2007.

20 ARANTES, Rogério Bastos. Ministério Público e Política no Brasil. São Paulo: Educ, Sumaré, Fapesp, 2002.

21 VIANNA, Luiz Werneck (org.). A democracia e os três poderes no Brasil. Belo Horizonte: UFMG, 2002.

22 ABREU, Alzira Alves de. O que é o Ministério Público? Rio de Janeiro: FGV, 2010.

23 SILVA, Cátia Aida. Promotores de justiça e novas formas de atuação em defesa de interesses sociais e coletivos. Revista Brasileira de Ciências Sociais, São Paulo, v. 16, n. 45, p. 127-144, fev. 2001.

${ }^{24}$ OLIVEIRA, Vanessa Elias de; LOTTA, Gabriela; VASCONCELOS, Natália Pires de. Ministério Público, autonomia funcional
} 
A independência funcional e a polissemia do termo interesse público, enquanto conceito jurídico indeterminado, concorrem para verificação dessa discricionariedade, refletindo no acesso à justiça, gerando a possibilidade de que Promotores e Procuradores escolham quais são os interesses e como serão protegidos. Assim, os membros do Ministério Público atuam como verdadeiros gatekeepers dos próprios serviços de justiça à população $0^{25}$, seja no âmbito estadual, seja no âmbito nacional.

Assim, incita-se a análise de sua atuação em contextos específicos, remetendo a aspectos legais, gerenciais e contingenciais que permeiam as políticas públicas, materializando concepções até então abstratas de eficiência, justiça e responsividade ${ }^{26}$.

Como se depreende, a discricionariedade do MP atinge o espectro alargado de atribuições e aparato do exercício de seu múnus, sobretudo quanto aos instrumentos extrajudiciais. Nesse contexto, analisamos a atuação institucional do MP e o exercício de suas funções considerando-se sua autonomia e atribuições para o enfrentamento da pandemia da COVID-19.

\section{Características da atuação do Ministério Público: autonomia e atribuições entre limites e possibilidades na crise sanitária}

Diante da pandemia provocada pelo novo coronavírus, os conflitos sociais evidenciaram-se no Brasil, requerendo-se, às vezes, a atuação do MP na defesa de Direitos Fundamentais e Sociais.

As medidas preventivas decorrentes da crise atingiram a convivência em comunidade em razão de sua transmissibilidade. Nesse contexto, emergiu a necessidade do isolamento e proteção sanitária em fronteiras entre países, até então minimizadas em face da globalização e seus intensos fluxos de mercadorias, pessoas e capitais.

Por sua vez, o Ministério Público teve suas fronteiras institucionais desafiadas para a defesa dos interesses metaindividuais, sobretudo, quando se demandam ações sobre políticas públicas com interferência em matéria originariamente reservada a gestores públicos. Nesse cenário, o debate em torno dos limites de atuação ministerial novamente ganhou destaque.

Em decorrência disso, a atuação do Conselho Nacional do Ministério Público (CNMP), por intermédio da Recomendação Conjunta PRESI-CN n. ${ }^{\circ}$ 2, de 18 de junho de 2020, evidenciou a legitimidade do Ministério Público para assegurar e defender, proativa e resolutivamente, os direitos fundamentais. Em seu texto, o órgão reafirmou a independência funcional de seus membros, ao passo que recomendou atenção para os limites das suas funções institucionais e a adoção de critérios na fiscalização de políticas públicas. A recomendação se destina a evitar a indevida invasão das atribuições alheias e a multiplicação de conflitos daí resultantes.

A referida recomendação se ampara no Estado Democrático de Direito brasileiro, voltado à garantia de direitos sociais como valores supremos de uma sociedade fraterna. Contudo, reconhece-se o aumento dos conflitos de atribuição entre os diversos ramos e unidades do Ministério Público no Brasil, o que se tornou mais evidente durante a pandemia provocada pelo novo coronavírus. Nesse sentido, o CNMP ressaltou que

e discricionariedade: ampla atuação em políticas públicas, baixa accountability. Revista de Estudos Empiricos em Direito, São Paulo, v. 7, n. 1, p. 181-195, abr. 2020.

${ }^{25}$ OLIVEIRA, Vanessa Elias de; LOTTA, Gabriela; VASCONCELOS, Natália Pires de. Ministério Público, autonomia funcional e discricionariedade: ampla atuação em políticas públicas, baixa accountability. Revista de Estudos Empíricos em Direito, São Paulo, v. 7, n. 1, p. 181-195, abr. 2020.

${ }^{26}$ OLIVEIRA, Vanessa Elias de; LOTTA, Gabriela; VASCONCELOS, Natália Pires de. Ministério Público, autonomia funcional e discricionariedade: ampla atuação em políticas públicas, baixa accountability. Revista de Estudos Empíricos em Direito, São Paulo, v. 7, n. 1, p. 181-195, abr. 2020. 
a efetivação das políticas públicas é atribuição exclusiva do Executivo, que o faz por meio de atos administrativos de gestão, reservando-se os atos judiciais ou de controle a finalidade distinta.

Nesse sentido, a recomendação do $\mathrm{CNMP}^{27}$ explicitou que "a função ministerial é de controle e não de execução, e a decisão administrativa é parte fundamental da cadeia de execução da política pública" de forma que "a decisão administrativa em geral, e na execução de políticas públicas em particular, é atribuição exclusiva do gestor".

De forma ainda mais evidente, o CNMP buscou orientar a conduta dos agentes ministeriais, destacando que a tomada de decisão acerca de um problema público cumpre ao gestor. Nesse sentido, a instituição aponta a necessidade de que promotores e procuradores busquem, em sua atuação, "compatibilizar a capacidade de iniciativa, a independência funcional dos membros do Ministério Público, a autonomia funcional e administrativa, a unidade do Ministério Público e a necessidade de uma atuação coordenada"28.

Diante de tais elementos, a instituição recomenda aos membros do Ministério Público brasileiro que atentem para os limites de suas funções institucionais, evitando-se a invasão indevida das atribuições de outros atores e a multiplicação de conflitos. Nesse sentido, cabe, igualmente, aos membros do MP respeitar a autonomia administrativa do gestor na fiscalização de atos de execução de políticas públicas. A resolução em comento é resultante de um debate que há algum tempo vem sendo explicitado por teóricos do tema.

$\mathrm{O}$ artigo $4^{\circ}$ da Resolução supracitada recomenda aos membros do Ministério Público brasileiro a ampliação do diálogo interinstitucional, especialmente com os órgãos fiscalizados, como meio de fortalecer o controle proativo e resolutivo da política pública, bem como viabilizar e racionalizar o acesso às informações.

Em outras palavras, a perspectiva de diálogo interinstitucional para dar maior efetividade às políticas públicas está de acordo com a ideia de Ministério Público resolutivo e mediador de conflitos discutida no âmbito teórico.

Nesse sentido e alinhado ao perfil constitucional desenhado para o Ministério Público, Goulart ${ }^{29}$ sustenta que existem dois modelos de Ministério Público: o demandista e o resolutivo. Para esse autor, o Ministério Público demandista atua perante o Poder Judiciário como agente processual, transferindo a esse órgão a resolução de problemas sociais. Enquanto o Ministério Público resolutivo atua no plano extrajurisdicional, como um grande intermediador e pacificador da conflituosidade social.

Em sua análise, em relação aos diversos avanços advindos do período posterior ao ano de 1988, o Ministério Público demandista é o que, ainda, prevalece, o que de certa forma, afirma o autor, é desastroso, já que o Judiciário, ainda, responde muito mal às demandas que envolvam os direitos massificados ${ }^{30}$.

Coelho e Kozicki ${ }^{31}$, por sua vez, refletiram sobre qual o papel destinado ao Ministério Público no que tange à resolução de problemas públicos. Os referidos autores partem de inquietação em torno da atuação ministerial como responsável pela criação de políticas públicas que foram sonegadas à sociedade civil, considerando-se que tais estratégias devem resultar de um processo complexo, que envolve tempo, equipamentos e recursos públicos.

Para os autores, a atuação ministerial que pauta o processo de formulação da política representa um excesso da atuação do Ministério Público. Dessa forma,

\footnotetext{
27 BRASIL. Conselho Nacional do Ministério Público. Recomendação Conjunta PRESI-CN ño 02, de 18 de junho de 2020. Disponível em: https://www.cnmp.mp.br/portal/atos-e-normas-separador/atos-e-normas-resultados Acesso em: 27 jan. 2021.

28 BRASIL. Conselho Nacional do Ministério Público. Recomendação Conjunta PRESI-CN no 02, de 18 de junbo de 2020. Disponível em: https://www.cnmp.mp.br/portal/atos-e-normas-separador/atos-e-normas-resultados Acesso em: 27 jan. 2021.

29 GOULART, Marcelo Pedroso. Ministério Público e democracia: teoria e práxis. São Paulo: Led Editora de Direito, 1998.

30 GOULART, Marcelo Pedroso. Ministério Público e democracia: teoria e práxis. São Paulo: Led Editora de Direito, 1998.

31 COELHO, Sérgio Reis; KOZICKI, Katya. O Ministério Público e as políticas públicas: definindo a agenda ou implementando as soluções?. Revista da AJURIS, Porto Alegre, v. 40, n. 130, p. 373-394, jun. 2013.
} 
A decisão judicial que julga procedente uma ação coletiva não tem, somente por esse motivo, ou seja, pela força da jurisdição, o poder de implementar uma política pública, substituindo, assim, o intrincado e demorado processo de sua formulação.

Como afirmam, a atuação do MP e as decisões judiciais devem restringir sua influência à definição da agenda, ressaltando os problemas a serem priorizados e pressionando a atuação estatal para a resolução dos conflitos $^{32}$.

$\mathrm{Na}$ concepção de Coelho e Kozicki ${ }^{33}$, a propósito de uma vocação democrática, o locus ministerial lida com problemas de distintas origens, dialoga com os mais diferentes grupos sociais e intermedia disputas e conflitos. Nesse sentido, a atuação do Ministério Público aprofunda o exercício de suas atribuições no intuito de resguardar o interesse público e de transformar a realidade.

Com base nisso, os autores aprofundam as análises e o debate acerca das duas classificações para a atuação do órgão ministerial sugerida por Goulart ${ }^{34}$ : Ministério Público demandista e Ministério Público resolutivo. A primeira refere-se à atuação tradicional perante o Poder Judiciário, "transferindo a este a resolução dos problemas sociais que chegam ao seu conhecimento". A segunda classificação relaciona-se à atuação extrajudicial, voltada à resolução de contendas sociais a partir de instrumentos próprios, previstos legalmente, a exemplo do termo de ajuste de conduta, as recomendações, os acordos extrajudiciais etc. ${ }^{35}$.

Aduzem, ainda, que ambas as atuações são fundamentais, quando realizadas na medida das competências o papel resolutivo exercido pelo Ministério Público é da maior relevância, principalmente nas questões que envolvem direitos coletivos, pois o Poder Judiciário brasileiro tem demonstrado certa aversão a esse tipo de ações, mesmo um despreparo para lidar com conflitos coletivos, o que se reflete no pequeno número de ações coletivas que são julgadas em comparação com as ações individuais, tornando imprescindível a atuação preventiva do Ministério Público ${ }^{36}$.

Alguns questionamentos importantes originam-se das reflexões dos autores, e, com base nelas, podemos refletir: qual seria a postura adequada do Ministério Público na interação com os atores que permeiam as políticas públicas? Coelho e Kozicki ${ }^{37}$ destacam ser inaceitável perceber o MP como um formulador ou um implementador de políticas públicas, devendo tal instituição, por sua vez, resguardar-se enquanto "um formador de pauta".

Para o debate em torno desse tema, as ideias de Da $\operatorname{Ros}^{38}$ nos oferecem outra possibilidade de análise. Para o referido autor, é possível perceber a atuação ministerial como órgão tutelar, órgão protetor ou órgão de mediação.

Na percepção como órgão tutelar, ressalta-se o papel negativo da atuação do órgão ministerial em face da sociedade civil. Isso porque, ao representar a sociedade civil, o Ministério Público buscaria substituí-la. Com isso, avoca-se, portanto, titular exclusivo com capacidade de proteger os interesses daquela e de agir em busca de um bem público que sobrepuja as motivações particulares.

\footnotetext{
32 COELHO, Sérgio Reis; KOZICKI, Katya. O Ministério Público e as políticas públicas: definindo a agenda ou implementando as soluções?. Revista da AJURIS, Porto Alegre, v. 40, n. 130, p. 373-394, jun. 2013. p.376.

33 COELHO, Sérgio Reis; KOZICKI, Katya. O Ministério Público e as políticas públicas: definindo a agenda ou implementando as soluções?. Revista da AJURIS, Porto Alegre, v. 40, n. 130, p. 373-394, jun. 2013.

34 GOULART, Marcelo Pedroso. Ministério Público e democracia: teoria e práxis. São Paulo: Led Editora de Direito, 1998.

35 COELHO, Sérgio Reis; KOZICKI, Katya. O Ministério Público e as políticas públicas: definindo a agenda ou implementando as soluções?. Revista da AJURIS, Porto Alegre, v. 40, n. 130, p. 373-394, jun. 2013. p. 385.

36 COELHO, Sérgio Reis; KOZICKI, Katya. O Ministério Público e as políticas públicas: definindo a agenda ou implementando as soluções?. Revista da AJURIS, Porto Alegre, v. 40, n. 130, p. 373-394, jun. 2013. p. 385.

37 COELHO, Sérgio Reis; KOZICKI, Katya. O Ministério Público e as políticas públicas: definindo a agenda ou implementando as soluções?. Revista da AJURIS, Porto Alegre, v. 40, n. 130, p. 373-394, jun. 2013. p. 391.

38 DA ROS, Luciano. Ministério público e sociedade civil no Brasil contemporâneo: em busca de um padrão de interação. Revista Política Hoje, Recife, v. 18, n. 1, 2009.
} 
Por sua vez, tem-se uma visão otimista quando se projeta sobre o Ministério Público uma função protetora de minorias e de diversos grupos componentes da sociedade civil. Sob essa ótica, explicita-se um potencial transformador da realidade social a partir de sua atuação. Nesse caso, o MP representa uma instância que possibilita o diálogo entre os movimentos sociais e o Estado, e potencializa mudanças na relação Sociedade-Estado e na realidade social. Desse modo, é possível denotar o empenho com um ideal profundo de transformação e não apenas com a convencional meta de representação de interesses.

O terceiro enquadramento, enquanto órgão mediador, se revela na hipótese de o Parquet não poder ser delimitado como substituto da sociedade civil, tampouco como agente impulsionador de transformações sociais relevantes. Acredita-se, nesse caso, na sua atuação como

Órgão de mediação entre vários setores da sociedade e do Estado, sendo capaz, por sua posição estratégica na arquitetura institucional, de promover coordenação entre vários grupos de interesses e movimentos sociais sem se tornar, contudo, insensível a eles. ${ }^{39}$

Como outra tipologia da atuação ministerial, destacam-se as classificações de Silva ${ }^{40}$, em Promotores de gabinete e Promotores de fatos, focando nas atribuições dos Promotores de Justiça dentro do campo dos interesses metaindividuais.

Com base no modelo institucional criado nas décadas de 1980 e 1990, a autora define promotor de gabinete como aquele que, embora faça uso de procedimentos extrajudiciais em seu mister, atribui magnitude à proposição de medidas judiciais e ao exame e parecer dos feitos judiciais de que se encarrega. Assim, este não utiliza os procedimentos extrajudiciais como ferramentas de negociação, articulação e mobilização. No entanto, não se esquiva de realizar fiscalizações e de propor iniciativas específicas diante de irregularidades ou denúncias.

Ao revés, o promotor de fatos prioriza o uso de procedimentos extrajudiciais, instigando recursos comunitários, provocando organismos governamentais e não-governamentais na condição de articulador político. Por isso, o uso contínuo daqueles procedimentos geraria vínculo estreito entre o membro ministerial e órgãos do governo. Além disso, o promotor de fatos teria de, por hábito, definir prioridades e estabelecer estratégias, inclinando-se à execução de projetos.

Ambos consideram as medidas judiciais como a última solução, em razão da lentidão e imprevisibilidade dos resultados. Contudo, podem ser verificadas posições distintas motivadas pela insatisfação com as respostas do Poder Judiciário por fatores diversos: o promotor de gabinete tende a evitar medidas judiciais relacionadas aos poderes públicos, ou seja, demandas que envolvam implementação de programas e serviços públicos. O promotor de fatos também evita a via judicial, mas explora os procedimentos extrajudiciais para mobilizar, articular, pressionar e negociar junto a organismos governamentais e não-governamentais, priorizando demandas de impacto coletivo e alargando o seu papel como agente que atua conjuntamente com organizações sociais e grupos locais ${ }^{41}$.

As tipologias referidas destacam-se como importantes balizadores para o estudo da atuação do Ministério Público nas mais diversas realidades. Nesse sentido, a seguir, analisaremos o caso do Rio Grande do Norte no contexto da pandemia da COVID-19.

\footnotetext{
39 DA ROS, Luciano. Ministério público e sociedade civil no Brasil contemporâneo: em busca de um padrão de interação. Revista Política Hoje, Recife, v. 18, n. 1, 2009. p. 42.

40 SILVA, Cátia Aida. Promotores de justiça e novas formas de atuação em defesa de interesses sociais e coletivos. Revista Brasileira de Ciências Sociais, São Paulo, v. 16, n. 45, p. 127-144, fev. 2001.

41 SILVA, Cátia Aida. Promotores de justiça e novas formas de atuação em defesa de interesses sociais e coletivos. Revista Brasileira de Ciências Sociais, São Paulo, v. 16, n. 45, p. 127-144, fev. 2001. p. 139.
} 


\section{Ministério Público do Rio Grande do Norte em tempos de pandemia}

O Estado do Rio Grande do Norte teve o primeiro caso confirmado do novo coronavírus em doze de março do ano de 2020, no dia seguinte à declaração de pandemia pela Organização Mundial de Saúde. Até o terceiro mês após o registro oficial da doença na China, não se verificava ainda transmissão local no Estado. Em vinte e oito de março do mesmo ano, na cidade de Mossoró/RN, ocorreu o primeiro óbito confirmado em razão do novo coronavírus.

Assim como no cenário nacional, os casos apresentaram alta a partir do mês de março, até julho de 2020. Quanto à taxa de transmissibilidade, a marca dos primeiros mil infectados foi atingida em quarenta e oito dias. Bastaram mais treze dias para dobrá-la e apenas mais nove dias para atingir quatro mil infectados. Em primeiro de julho de 2020, nos termos do Informe Epidemiológico Coronavírus (Covid-19) n. ${ }^{\circ} 101^{42}$, todas as 167 (cento e sessenta e sete) cidades potiguares registraram casos confirmados do novo coronavírus.

Em razão da pandemia, a rotina dos potiguares foi modificada. Nesse período, serviços deixaram de ser prestados presencialmente, órgãos públicos alteraram o horário e modo de funcionamento; escolas públicas interromperam o ano letivo, eventos foram suspensos e o comércio fechado. Na primeira quinzena de maio de 2020, os reflexos na rede hospitalar começaram a ser percebidos com superlotação e falta de leitos de UTI para tratamento de casos da COVID-19 na rede pública estadual de saúde da capital ${ }^{43}$.

De acordo com o Informe Epidemiológico Coronavírus (Covid-19) n. ${ }^{\circ} 137^{44}$, o número de óbitos por COVID-19 acumulados até doze de agosto de 2020 alcançou 2.019 (duas mil e dezenove) ocorrências. Em comparação com dados da violência no Estado, superou os números de vítimas por homicídio verificados nos anos 2018 e 2019: 1.963 (mil novecentos e sessenta e três) e 1.446 (mil quatrocentos e quarenta e seis) vítimas, respectivamente ${ }^{45}$.

De junho a setembro de 2020, o RN repetiu o comportamento epidemiológico dos demais Estados nordestinos. Nesse sentido, alcançou-se um pico principal da primeira onda de infecção em junho e julho, seguido de uma queda sistemática e alongada, em um comportamento típico do processo de infecções diárias, constantes e sustentadas ${ }^{46}$.

Ao longo do referido período, foram identificados conflitos relativos ao atendimento aos infectados, bem como em relação às medidas que buscavam frear o contágio, a exemplo da suspensão de funcionamento das atividades econômicas. Se, de um lado, foi possível identificar a ocorrência de parcerias entre o governo estadual e universidades ${ }^{47}$ na busca por soluções para as crises geradas pela COVID-19; por outro lado, as discordâncias entre entes públicos e destes com o setor privado foram marcantes ${ }^{48}$.

${ }^{42}$ RIO GRANDE DO NORTE. Secretaria de Estado de Saúde Pública. Informe Epidemiológico Coronavírus (Covid-19) $n^{\circ}$ 101, 01/07/2020. Disponível em: http://www.adcon.rn.gov.br/ACERVO/sesap/DOC/DOC000000000234435.PDF Acesso em: 10 fev. 2021.

${ }^{43}$ CECI, Mariana. Leitos gerais públicos de UTI estão lotados em Natal, diz SES AP. 2020. Disponível em: http:/ /www.tribunadonorte. com.br/noticia/leitos-gerais-paoblicos-de-uti-esta-o-lotados-em-natal-afirma-sesap-rn/479618 Acesso em: 11 fev. 2021.

44 RIO GRANDE DO NORTE. Secretaria de Estado de Saúde Pública. Informe Epidemiológico Coronavírus (Covid-19) $n^{\circ}$ 137, 12/08/2020. Disponível em: http://www.adcon.rn.gov.br/ACERVO/sesap/DOC/DOC000000000237557.PDF Acesso em: 10 fev. 2021.

${ }^{45}$ GOMES, Luiz Henrique. Em cinco meses, covid matou mais que a violência no RN. Tribuna do Norte, 2020. Disponível em: http://www.tribunadonorte.com.br/noticia/em-cinco-meses-covid-matou-mais-que-a-viola-ncia-no-rn/487192. Acesso em: 11 fev. 2021.

46 NASCIMENTO JUNIOR, José Dias do. RN tem pico de infecção sem precedentes e contabilizados na semana de 15 de outubro de 2020. 2020. Disponível em: https://jd-donascimento.medium.com/rn-tem-pico-de-contamina $\%$ C3\%A7\%C3\%A3o-sem-precedentesna-semana-de-15-de-outubro-cd9651dd05c5 Acesso em: 10 fev. 2021.

47 ALMEIDA, Lindijane de Souza Bento et al. As universidades públicas brasileiras no contexto da pandemia: iniciativas e parcerias no enfrentamento da covid-19. Cadernos Gestão Pública e Cidadania, São Paulo, v. 25, n. 82, p. 82-100, set./dez. 2020.

48 SILVEIRA, Raquel Maria da Costa et al. Governança metropolitana em tempos de pandemia. In: CLEMENTINO, Maria do Livramento; ALMEIDA, Lindijane; SILVA, Brunno (orgs.). Em tempos de pandemia: contribuições do Observatório das Metrópoles: núcleo Natal. Rio de Janeiro: Letra Capital, 2020. 
Seja nos contextos de parcerias ou na mediação de conflitos, foi possível visualizar a atividade frequente do MPRN. Para fins de análise, o estudo da atuação do Ministério Público do Rio Grande do Norte, durante a pandemia da COVID-19, pautou-se na sistematização do conteúdo noticiado no portal de notícias http:// www.mprn.mp.br/portal/inicio/noticias entre treze de março e treze de setembro de 2020. Ao todo, foram reportadas 152 (cento e cinquenta e duas) atividades, que não totalizam o universo da prática do MPRN no período, mas representam os destaques conferidos pela própria instituição.

O número de notícias relativas à pandemia da COVID-19 reportadas pelo sítio eletrônico reduziu-se ao longo dos meses, o que pode estar relacionado com a queda do número de casos no estado. Em março de 2020, 46 (quarenta e seis) atuações foram reportadas, enquanto que em agosto (último mês completo considerado na pesquisa), apenas 4 (quatro) foram atividades noticiadas. Até o dia treze de setembro, apenas 2 (duas) notícias haviam sido veiculadas.

A atuação do MPRN no período analisado se deu de forma, majoritariamente, extrajudicial. Do universo pesquisado, foram 138 (cento e trinta e oito) notícias de atuação ministerial fora do Poder Judiciário, correspondentes a 90,7\% (noventa vírgula sete por cento) e 14 (catorze) reportagens que evidenciaram a judicialização, equivalente a 9,3\% (nove vírgula três por cento). O gráfico abaixo evidencia que a atuação extrajudicial (relacionada com a COVID-19) teve forte declínio a partir do mês de abril, quando a atuação judicial iniciou discreto aumento.

Gráfico 1 - classificação da atuação do MPRN (março a setembro de 2020)

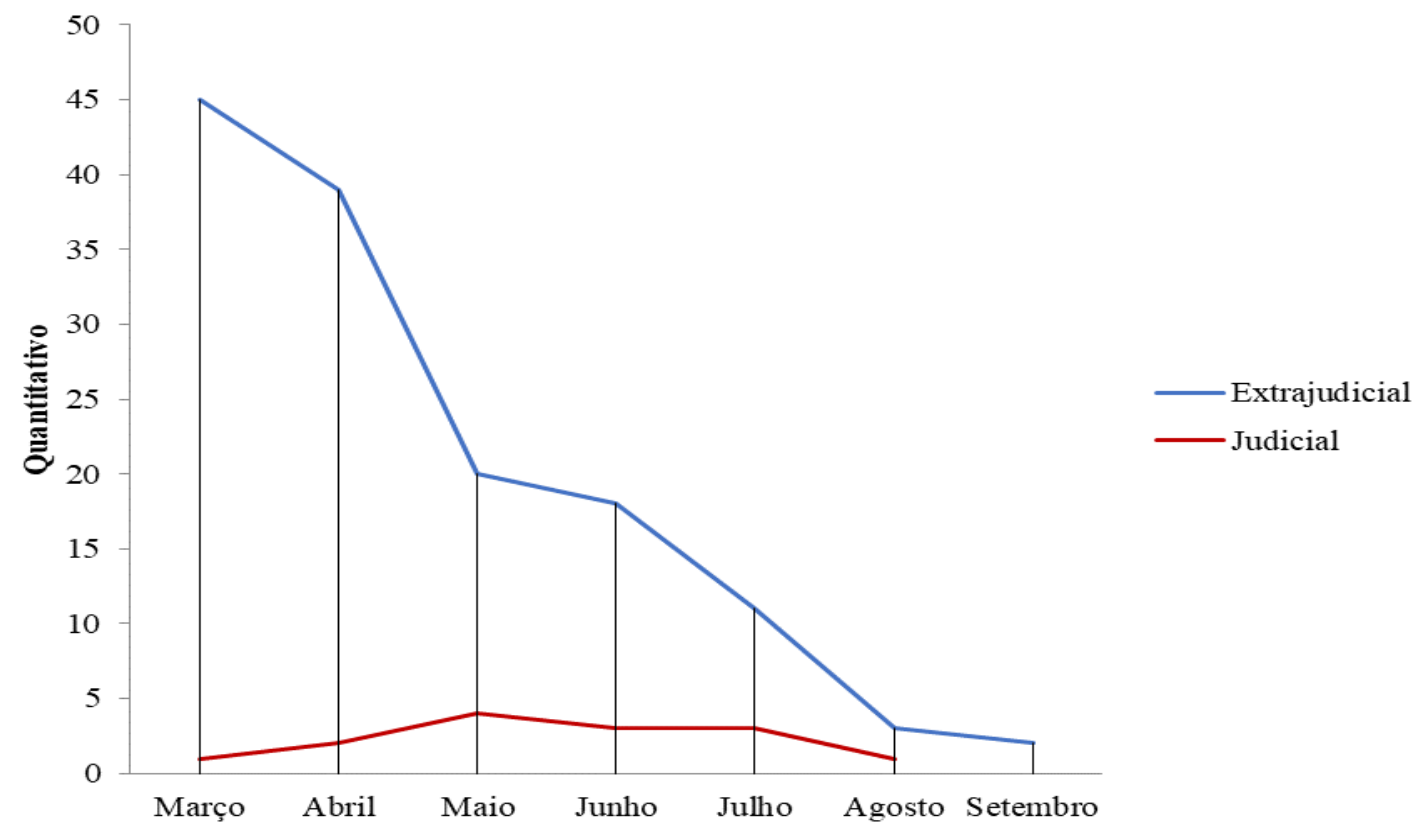

Fonte: elaboração própria com dados da pesquisa (2021).

Com foco tão somente no perfil de atuação, vale ressaltar que, no Gráfico 1, revela-se uma preferência do MPRN, ao decorrer do enfrentamento da crise sanitária, por medidas judiciais a partir do agravamento do cenário epidemiológico. A interpretação do gráfico não significa baixa atuação ministerial, mas sim apenas a redução do número de reportagens relativas à pandemia no período, inferindo-se uma atuação mais voltada ao monitoramento das políticas públicas do que à proposição de novas demandas.

Considerando-se o universo de notícias, é possível perceber que a maior parte da atuação estava voltada à adoção de medidas pelo poder público, seja em virtude da omissão ou de uma medida reportada como ilegal. Do total de 152 (cento e cinquenta e duas) atuações reportadas, 96 (noventa e seis), correspondentes a 63\% (sessenta e três por cento), tinham como objeto a atuação estatal; 24 (vinte e quatro) enfocaram entidades particulares, equivalente a 15\% (quinze por cento); 2 (duas) delas, ou seja 1,3\% (um vírgula três por cento), 
voltaram-se ao poder público e a particulares simultaneamente; e 30 (trinta), cerca de 6,5\% (seis vírgula cinco por cento), consistiram em medidas internas ou na divulgação de serviços realizados pelo MPRN (Gráfico 2).

Gráfico 2 - quantitativo de atuações por objeto e mês

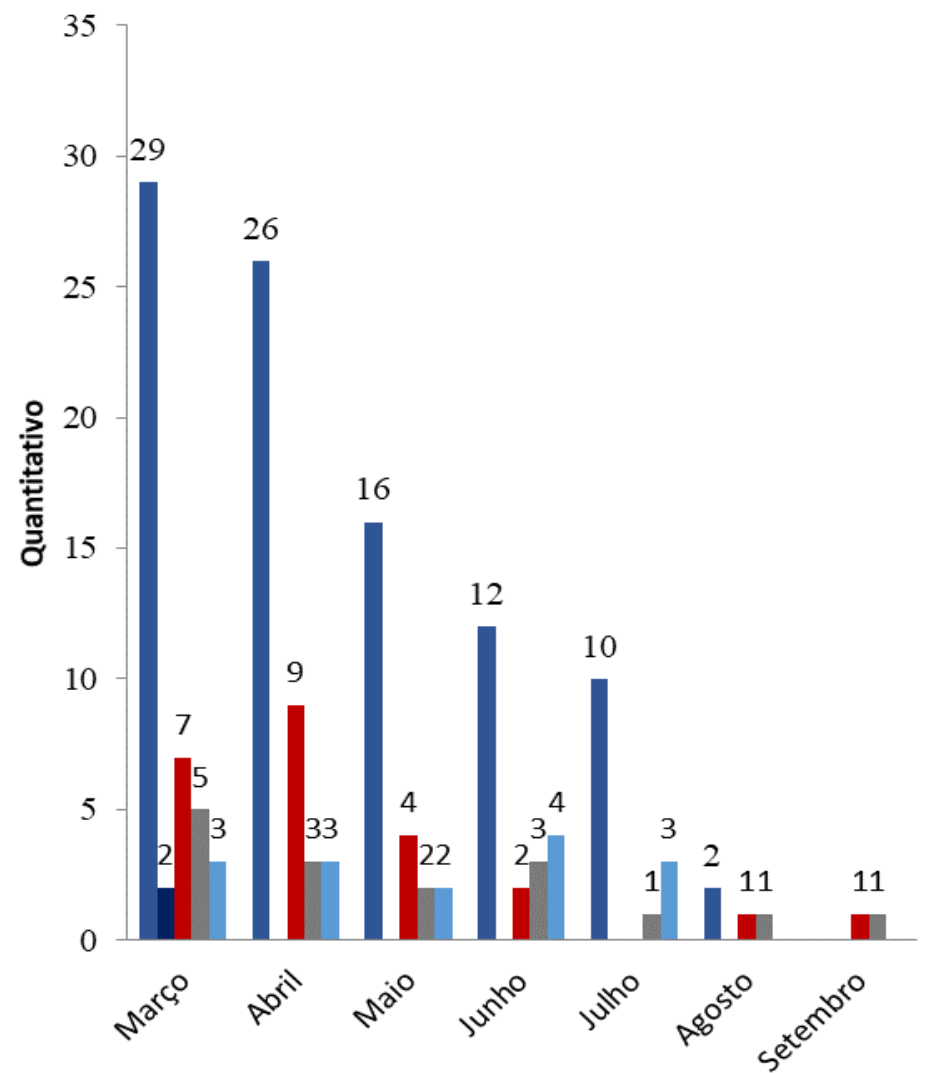

- Adoção de medidas pelo poder público

- Adoção de medidas pelo poder público e particulares

- Adoção de medidas por particulares

- Medidas internas

* Serviço ao cidadão

Fonte: elaboração própria com dados da pesquisa (2021).

Os entes municipais foram os atores mais demandados, seja judicial ou extrajudicialmente. O Gráfico 3 apresenta a distribuição do quantitativo de notícias considerando a classificação dos atores em categorias gerais. O rótulo "não se aplica" equivale a atuações administrativas internas, serviços ao cidadão e medidas que não se destinavam diretamente a nenhum ator específico. Ao todo, 74 (setenta e quatro) atuações envolviam entes municipais e 21 (vinte e uma) destinavam-se ao Governo do RN. A maior parte dessas atuações ocorreu entre os meses de março a junho e foram medidas extrajudiciais. 
Gráfico 3 - atores demandados pelo MPRN por tipo de atuação e mês de análise (março a setembro de 2020)

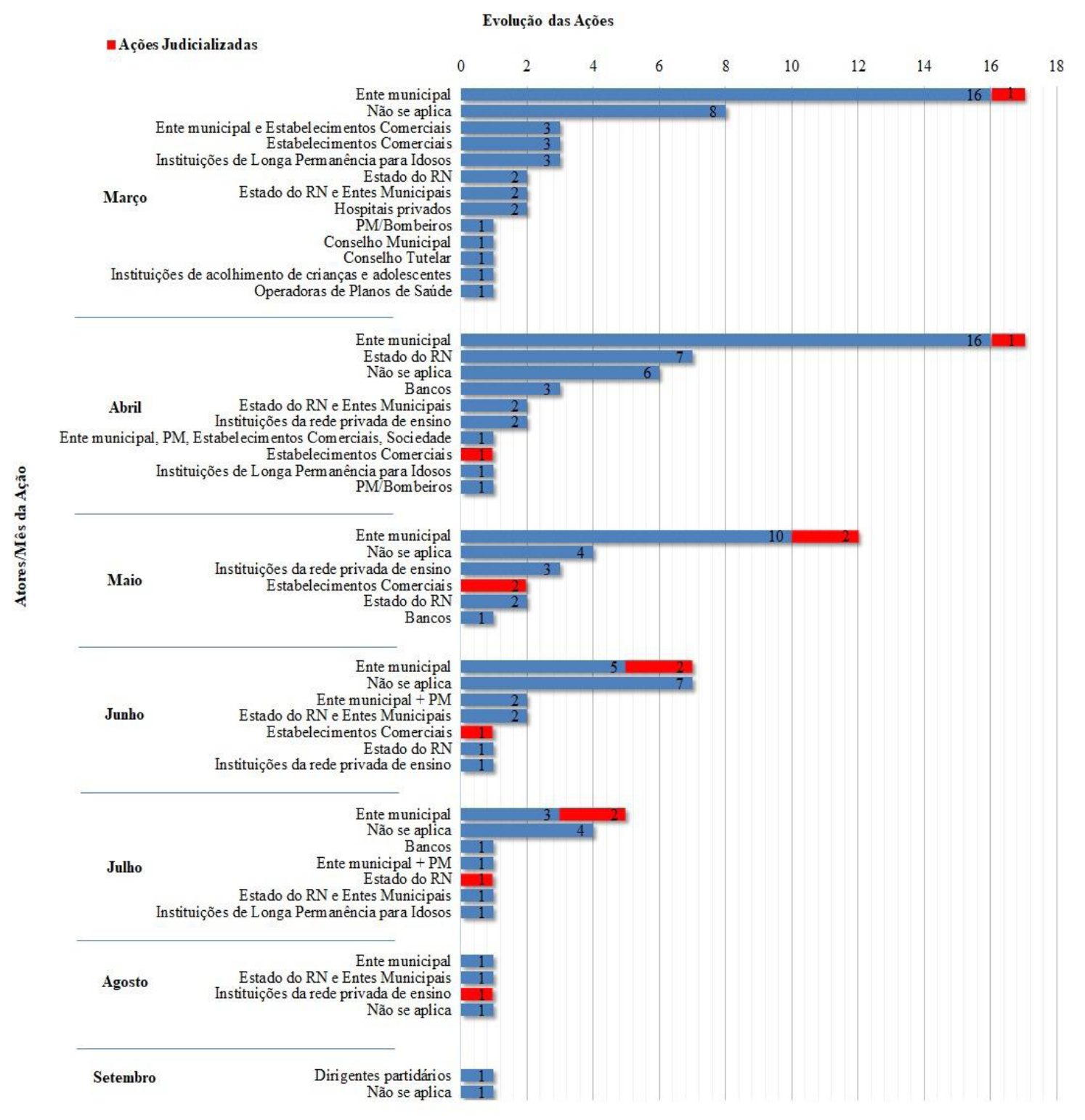

Quantitativo de Ações

Fonte: elaboração própria com dados da pesquisa (2021).

Foram catalogados 10 (dez) tipos de atuação: ajuizamento de ação civil pública (ACPs); colaboração com instituições; determinação interna; instauração de procedimento; nota conjunta; operação; orientação; recomendação; serviço ao cidadão e termo de ajustamento de conduta. A principal forma de atuação do MPRN entre os primeiros meses de pandemia foi a emissão de recomendação. Foram 90 (noventa) recomendações entre os meses pesquisados e 68\% (sessenta e oito por cento) delas (61 atos) se concentraram entre os meses de março e abril de 2020, os quais correspondem aos primeiros dois meses de pandemia no estado. Em seguida, o segundo maior número de atuações se deu por determinações administrativas internas (16), concentradas entre os meses de março e junho (13), e o terceiro por meio de ações civis públicas, que totalizaram 13, concentradas, em sua maior parte (10 ACPs), nos meses de maio a julho de 2020. 
Tabela 1 - quantitativo de atuações por tipo e mês (março a setembro de 2020)

\begin{tabular}{|c|c|c|c|c|c|c|c|c|}
\hline Tipos de atuação & Março & Abril & Maio & Junho & Julho & Agosto & Setembro & $\begin{array}{l}\text { Total } \\
\text { geral }\end{array}$ \\
\hline Recomendação & 32 & 29 & 13 & 9 & 5 & 1 & 1 & 90 \\
\hline $\begin{array}{l}\text { Determinação } \\
\text { interna }\end{array}$ & 5 & 3 & 2 & 3 & 1 & 1 & 1 & 16 \\
\hline Serviço ao cidadão & 4 & 2 & 2 & 4 & 2 & & & 14 \\
\hline $\mathrm{ACP}$ & 1 & 1 & 4 & 3 & 3 & 1 & & 13 \\
\hline TAC & 1 & 3 & 3 & 1 & 1 & 1 & & 10 \\
\hline $\begin{array}{l}\text { Colaboração com } \\
\text { instituições }\end{array}$ & & 2 & & 1 & 1 & & & 4 \\
\hline Nota conjunta & 1 & & & & 1 & & & 2 \\
\hline $\begin{array}{l}\text { Instauração de } \\
\text { procedimento }\end{array}$ & 1 & & & & & & & 1 \\
\hline Operação & & 1 & & & & & & 1 \\
\hline Orientação & 1 & & & & & & & 1 \\
\hline Total geral & 46 & 41 & 24 & 21 & 14 & 4 & 2 & 152 \\
\hline
\end{tabular}

Fonte: elaboração própria com dados da pesquisa (2021).

Das 90 (noventa) recomendações emitidas, 70 (setenta) tinham como objeto a atuação do poder público, equivalente a 78\% (setenta e oito por cento); 18 (dezoito), ou seja, 20\% (vinte por cento), voltavam-se ao setor privado e 2 (duas) delas, ou 2,2\% (dois vírgula dois por cento), enfocaram a ação dos dois setores.

A atuação do MPRN foi difusa em todo o território estadual, embora as notícias tenham apontado uma concentração em Natal (a capital do estado) e Mossoró, as duas cidades mais populosas do RN. Para fins de análise, o mapa foi subdividido em 3 (três) regiões geográficas intermediárias, observando os núcleos urbanos principais e as cidades hierarquicamente dependentes: as regiões de Natal, Mossoró e Caicó. A região que tem como polo Natal abriga 75 (setenta e cinco) municípios e abrangeu 79 (setenta e nove) medidas, seguida pela região de Mossoró, com 68 (sessenta e oito) municípios e 59 (cinquenta e nove) menções nas reportagens e Caicó, que abrange 24 (vinte e quatro) municípios e 14 (quatorze) medidas. É possível perceber que o polo das regiões destacadas coincidiu com as localidades com o maior quantitativo de notícias reportadas, com exceção de Caicó. Na Região Metropolitana de Natal, por sua vez, destacaram-se os municípios de Natal e Parnamirim, primeiro e terceiro mais populosos do estado, respectivamente, concentrando, também, a atuação do MP durante o período analisado. 
Mapa 1 - distribuição das medidas reportadas pelo MPRN no território do estado

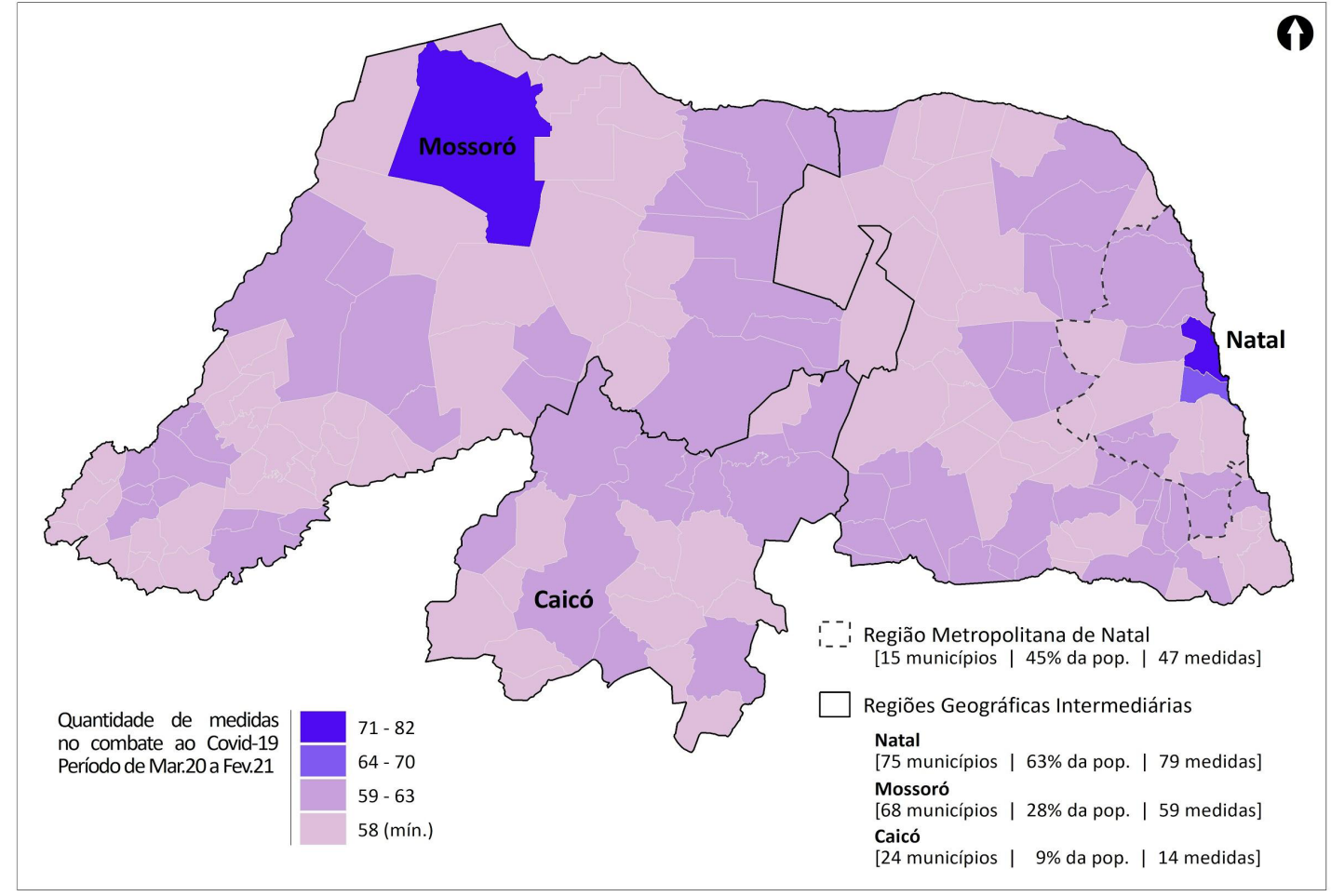

Fonte: elaboração própria com dados da pesquisa (2021).

As distintas gradações refletem o maior ou menor destaque conferido pelo portal de notícias em relação às atividades das promotorias, o que, por sua vez, pode ser decorrência de compassos e dinâmicas de atuação diferentes existentes na própria instituição. Tais diferenças também decorrem da autonomia conferida aos membros do MP e podem ser relacionadas como um efeito da discricionariedade que pode levar a desigualdades inscritas no próprio território.

Ainda buscando compreender o contexto em análise, foi elaborada uma classificação das reportagens de acordo com o fundamento e a finalidade. Com base nesse esforço, foi possível identificar que a maior parte da atuação se fundamentava no direito à saúde, sendo acompanhadas das medidas administrativas e da atuação voltada à garantia do direito do consumidor e com foco na suspensão de atividades. 
Gráfico 4 - classificação das atividades por área de políticas públicas (março a setembro de 2020)

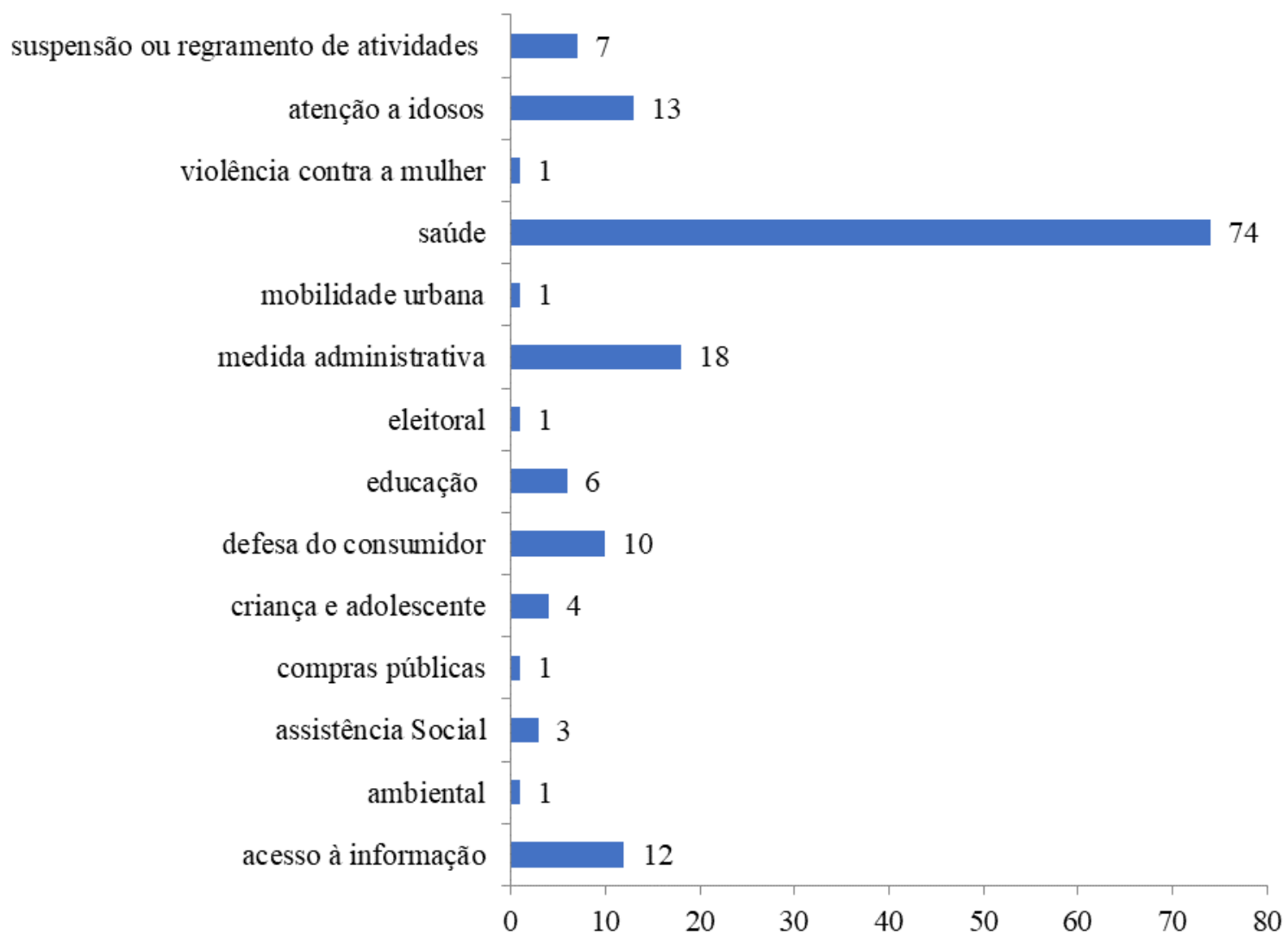

Fonte: elaboração própria com dados da pesquisa (2021).

Por fim, a pesquisa ainda se interessou em compreender a qual etapa das políticas públicas a atuação do MPRN se relacionava. A divisão de etapas se baseou no modelo de análise do ciclo de políticas públicas, o qual consiste em uma ferramenta heurística que subdivide o agir público em fases do processo político-administrativo. Há diferenças nas divisões das etapas na literatura sobre o tema. Por exemplo, Frey ${ }^{49}$ destaca as fases de percepção e definição de problemas, "agenda-setting", elaboração de programas e decisão, implementação de políticas e, finalmente, a avaliação e a eventual correção da ação.

Na primeira etapa de percepção e definição de problemas, Frey ${ }^{50}$ se refere a um grande número de demandas que se mostram apropriadas para um tratamento político. A etapa da "agenda-setting" é aquela em que uma demanda se torna, de fato, uma questão política a ser priorizada ou, como possibilidade, pode ser excluída ou adiada para um momento posterior. Na terceira etapa, elaboração de programas e de decisão, são escolhidas as alternativas para sanar os problemas e as questões políticas. Já a etapa de implementação consiste no momento de execução do planejamento realizado, organizando-se o aparelho administrativo e os recursos humanos, financeiros, materiais e tecnológicos para a concretização dos fins desejados. Por fim, a avaliação consiste em um julgamento acerca dos efeitos gerados pelas políticas, considerando critérios diversos como a eficiência, a eficácia e a efetividade.

\footnotetext{
${ }^{49}$ FREY, Klaus. Políticas públicas: um debate conceitual e reflexões referentes à prática da análise de políticas públicas no Brasil. Revista Planejamento e Políticas Públicas, Brasília, n. 21, p. 211-259, jun. 2000.

${ }^{50}$ FREY, Klaus. Políticas públicas: um debate conceitual e reflexões referentes à prática da análise de políticas públicas no Brasil. Revista Planejamento e Políticas Públicas, Brasília, n. 21, p. 211-259, jun. 2000.
} 
De forma adaptada, na presente análise, as etapas foram consideradas como: definição de problemas; formulação; implementação; monitoramento e avaliação. Com base nos dados coletados, apenas 3 (três) fases concentraram a atuação do órgão pesquisado:

Gráfico 5 - distribuição da atuação por etapas das políticas públicas

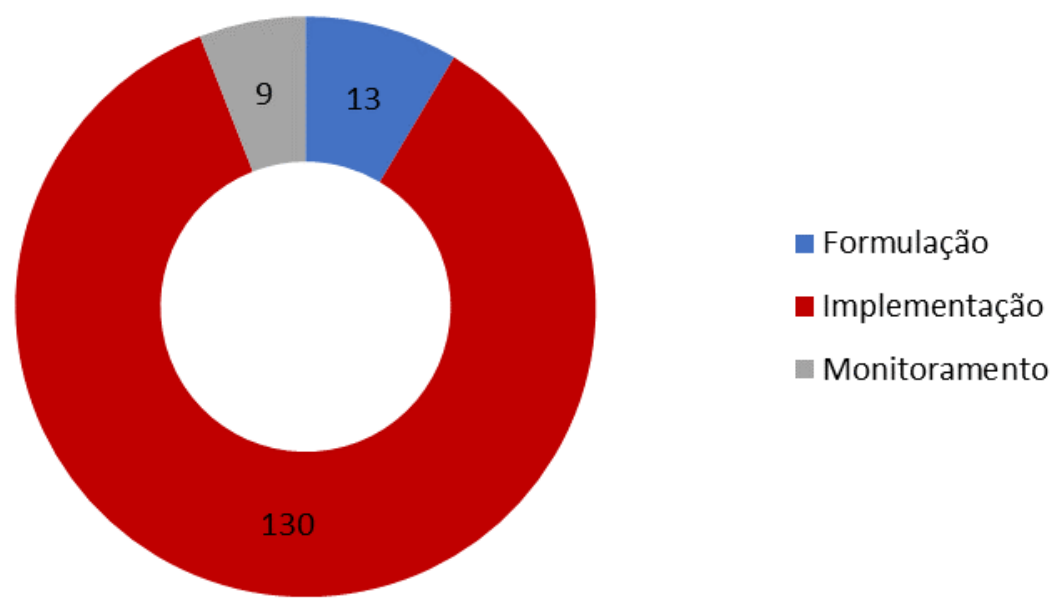

Fonte: elaboração própria com dados da pesquisa (2021).

As medidas relativas à formulação, em regra, orientaram a adoção de novas estratégias de prevenção ao contágio do novo coronavírus; a elaboração e atualização de planos, programas, projetos e normativos, bem como a adoção de medidas (como a realização de campanhas). No âmbito da implementação, a atuação baseou-se na efetivação de normativos existentes e de políticas já formuladas, reforçando a importância de que as atividades de atores públicos e/ou privados observassem as diretrizes. No que tange ao monitoramento, destacam-se as ações de fiscalização, bem como aquelas que recomendaram a ação fiscalizatória por parte de organizações públicas.

Das 13 (treze) medidas constatadas na fase da formulação, nenhuma delas apresentou uma atuação que extrapolasse a competência fiscalizatória da instituição. As medidas restringiam-se a recomendar e orientar sobre a necessidade de adoção de medidas, sem estabelecer o conteúdo das políticas, respeitando-se, portanto, a atribuição exclusiva do Poder Executivo como responsável pela formulação das estratégias. Dessa forma, foi possível identificar o MPRN como "um formador de pauta" 51 , afastando-se de uma postura de mero formulador ou apenas implementador de políticas públicas. Assim, foi possível destacar o cumprimento e a observância da Recomendação Conjunta PRESI-CN n. ${ }^{\circ}$ 2, de 18 de junho de 2020 (CNMP) em âmbito estadual no período pesquisado.

Após a visualização do cenário, com base nos dados apresentados, foi possível constatar, em síntese, uma atuação concentrada nos primeiros meses de pandemia (março a junho) e marcadamente extrajudicial. Entre março e agosto, a atuação teve como objeto principal as ações do poder público, existindo medidas, em menor proporção, voltadas às atividades do setor privado. No setor público, o destaque foram as medidas que abrangiam entes municipais como foco da atuação, seguindo-se do Governo Estadual. A maior parte delas, por sua vez, caracterizou-se como atuação extrajudicial voltada a ambas as escalas de governo. Foram 90 (noventa) recomendações expedidas no período pesquisado, contra 13 (treze) ACPs protocoladas em

51 COELHO, Sérgio Reis; KOZICKI, Katya. O Ministério Público e as políticas públicas: definindo a agenda ou implementando as soluções? Revista da AJURIS, Porto Alegre, v. 40, n. 130, p. 373-394, jun. 2013. p. 391. 
desfavor de entidades públicas. As medidas adotadas abrangiam diversas áreas de atuação, concentrando-se, na etapa da implementação, ou seja, exigindo-se a execução de diretrizes já existentes.

O cenário estudado permitiu notar que, diante da pandemia, o poder discricionário do MPRN ${ }^{52}$ foi exercido e reafirmado, de forma geral, no sentido da pactuação. Os elementos contingenciais, certamente, favoreceram tal postura, confirmando os aspectos destacados por Oliveira, Lotta e Vasconcelos ${ }^{53}$. No período da pesquisa, a discussão sobre o pacto federativo brasileiro esteve em evidência e o RN demonstrou casos que se classificaram como dissensos entre os entes municipais e o Governo Estadual. No seio dessas contendas, o MPRN atuou de forma a mediar tais conflitos entre os entes, bem como entre os setores público e privado ${ }^{54}$.

A discricionariedade explicitou-se, inclusive, com base em dissensos evidenciados dentro da própria instituição que, embora tenham sido evidenciados após o recorte temporal desta pesquisa, merecem ser relatados. Já em 2021, após a publicação de novas medidas de contenção ao contágio do novo coronavírus pelo governo estadual (Decreto n. 30.383 de 26 de fevereiro de 2021) divergentes das adotadas pela Prefeitura de Natal (Decreto n. ${ }^{\circ}$ 12.179, de 6 de março de 2021), foi noticiada a impetração de Mandado de Segurança por promotor de Justiça da capital. O writ requereu a suspensão do toque de recolher estadual imposto e explicitou discordâncias entre o ente estadual e o Prefeito de Natal (contrário à restrição), notabilizando, também, a discricionariedade dos membros do MP, a qual pode, inclusive, gerar distintos posicionamentos internos.

No caso relatado, conforme noticiado pela mídia local, o Procurador-geral de Justiça (PGJ), atento ao agravamento da crise no estado, e considerando a relação de colaboração entre instituições, que vinha configurando a gestão da pandemia pelo Governo estadual, adentrou no processo, solicitando a desistência da ação e a sua extinção sem resolução do mérito ${ }^{55}$. O argumento utilizado para tanto trazia elementos processuais como motivação, apontando-se que a competência para a impetração de mandado de segurança em desfavor de ato da Governadora perante o Tribunal de Justiça do RN seria do Procurador-geral de Justiça. Contudo, a leitura atenta do pedido de desistência interposto pelo PGJ demonstra a existência de entendimento, sobre a necessidade e legalidade do toque de recolher imposto pelo decreto estadual, contrário àquele defendido pelo Promotor de Justiça, na medida em que afirmou o PGJ ${ }^{56}$ :

por outro lado, ressalte-se que $019^{\circ}$ Promotor de Justiça da Comarca de Natal/RN, visando persuadir este Egrégio TJ-RN de que o estabelecimento do "toque de recolher" pelo decreto vergastado seria ilegal e inconstitucional, interpreta, equivocadamente, decisão proferida pelo Supremo Tribunal Federal nos autos da ADPF $n^{\circ}$ 672, que estabelece em sua parte dispositiva, claramente, a possibilidade de os Governos Estaduais, Distrital e Municipais, adotarem medidas restritivas à circulação de pessoas durante a pandemia, como forma de reduzir o número de infectados e de óbitos decorrentes da COVID-19.

Observou-se que a impetração do mandado de segurança significou o afastamento do Promotor de Justiça de uma função voltada à mediação, postura que caracterizou a atuação do MPRN durante a crise no

\footnotetext{
52 OLIVEIRA, Vanessa Elias de; LOTTA, Gabriela; VASCONCELOS, Natália Pires de. Ministério Público, autonomia funcional e discricionariedade: ampla atuação em políticas públicas, baixa accountability. Revista de Estudos Empíricos em Direito, São Paulo, v. 7, n. 1, p. 181-195, abr. 2020.

53 OLIVEIRA, Vanessa Elias de; LOTTA, Gabriela; VASCONCELOS, Natália Pires de. Ministério Público, autonomia funcional e discricionariedade: ampla atuação em políticas públicas, baixa accountability. Revista de Estudos Empiricos em Direito, São Paulo, v. 7 , n. 1, p. 181-195, abr. 2020.

54 SILVEIRA, Raquel Maria da Costa et al. Governança metropolitana em tempos de pandemia. In: CLEMENTINO, Maria do Livramento; ALMEIDA, Lindijane; SILVA, Brunno (orgs.). Em tempos de pandemia: contribuições do Observatório das Metrópoles: núcleo Natal. Rio de Janeiro: Letra Capital, 2020.

55 MP-RN desautoriza promotor e pede desistência de ação que analisa toque de recolher. Jurinews, 2021. Disponível em: https://jurinews.com.br/fogo-no-parquinho/mp-rn-desautoriza-promotor-e-pede-desistencia-do-ms-que-analisa-toque-de-recolher/ Acesso em: 12 mar. 2021.

56 RIO GRANDE DO NORTE. Tribunal de Justiça do Estado do Rio Grande do Norte (Tribunal Pleno). Pedido de desistência em Mandado de Segurança Cível ñ 0800094-47.2021.8.20.5400. Relator: Des. Dirlemando Mota, 09 de março de 2021. Disponível em: https://jurinews.com.br/wp-content/uploads/2021/03/Pedido-do-PGJ-de-desist\%C3\%AAncia-do-MS.pdf Acesso em: 12 mar. 2021.
} 
estado. Por outro lado, a enérgica medida do Procurador Geral de Justiça reafirmou as bases da colaboração e o perfil identificado pela presente pesquisa. Contudo, o ocorrido representa a discricionariedade em seu sentido mais explícito. Se, por um lado, tal característica, decorrente da autonomia e independência funcional, pauta as escolhas acerca de quais casos “devem (e como devem) ser levados adiante pelo MP” e, dessa forma, "acabam abrindo ou fechando portas do Estado para determinados tipos de causas e de cidadãos" 57 , o estudo do contexto potiguar evidenciou que tal característica pode, também, ser determinante para a própria coesão institucional.

Conforme destacado por Oliveira, Lotta e Vasconcelos ${ }^{58}$, é justamente a independência funcional que gera a possibilidade de que cada membro possa definir suas prioridades e criar seus próprios métodos de atuação. Tal elemento marca a presença do MPRN na pandemia da COVID-19, sendo possível identificar que as diferentes formas de atuação decorrem de ideias, valores e percepções individuais sobre a crise.

Tais elementos, além de embasarem dissonâncias de atuações internas, também expressaram posicionamentos divergentes entre os atores do sistema de Justiça do estado. Nesse sentido, colaciona-se trecho da decisão Judicial que acatou a desistência requerida pelo MPRN e, ao mesmo tempo, explicitou a opinião do julgador acerca da política:

a esse respeito, ressalto, a título de obiter dictum, que, muito embora seja lícito ao Impetrante desistir, a qualquer momento, do mandado de segurança, e apesar do reconhecimento da legitimidade ativa do Procurador-Geral de Justiça como representante do Ministério Público para o presente mandado de segurança coletivo, o presente pedido de desistência não se conforma, a meu ver, com a necessária função institucional do Parquet na defesa da ordem democrática e dos direitos individuais indisponíveis. ${ }^{59}$

A despeito de casos pontuais, como o acima referido, de modo geral, o estudo realizado permitiu identificar uma atuação aproximada da classificação de um "Ministério Público Resolutivo" ${ }^{60}$, considerando-se a massiva atividade extrajudicial identificada por meio das 90 (noventa) recomendações noticiadas. Além disso, o perfil extrajudicial permitiu identificar os membros como "promotores de fatos" ${ }^{61}$, os quais, durante o período da pesquisa, estimularam e provocaram organismos governamentais, privados e não governamentais na condição de articuladores políticos e, também, de mediadores.

Ademais, nesse contexto, o Ministério Público do Rio Grande do Norte firmou importantes articulações interinstitucionais para acompanhar as medidas de enfrentamento à pandemia, bem como tem participado ativamente do comitê estadual que avalia diariamente o quadro da proliferação do vírus no estado. Como resultado desse esforço, a instituição publicou seis resoluções e três atos conjuntos, disciplinando as formas de trabalho para garantir a preservação da saúde de todos os integrantes e assegurar a prestação de serviço de qualidade para a população.

Entre as ações voltadas ao público, foi criada a Central de Atendimento ao Cidadão, que recebe as manifestações da população por meio de Whatsapp, ligação telefônica e correio eletrônico. Além disso, no site

\footnotetext{
57 OLIVEIRA, Vanessa Elias de; LOTTA, Gabriela; VASCONCELOS, Natália Pires de. Ministério Público, autonomia funcional e discricionariedade: ampla atuação em políticas públicas, baixa accountability. Revista de Estudos Empiricos em Direito, São Paulo, v. 7, n. 1, p. 181-195, abr. 2020. p. 186.

58 OLIVEIRA, Vanessa Elias de; LOTTA, Gabriela; VASCONCELOS, Natália Pires de. Ministério Público, autonomia funcional e discricionariedade: ampla atuação em políticas públicas, baixa accountability. Revista de Estudos Empiricos em Direito, São Paulo, v. 7, n. 1, p. 181-195, abr. 2020.

59 RIO GRANDE DO NORTE. Tribunal de Justiça do Estado do Rio Grande do Norte. Decisão monocrática em Mandado de Segurança Civel no 0800094-47.2021.8.20.5400. Relator: Des. Dirlemando Mota, 12 de março de 2021. Disponível em: https://jurinews.com. br/wp-content/uploads/2021/03/DECIS\%C3\%83O-MS-coletivo-ilegitimidade-ativa-PmJ-homologa-desist\%C3\%AAncia-PGJ. pdf Acesso em: 12 mar. 2021.

${ }^{60}$ COELHO, Sérgio Reis; KOZICKI, Katya. O Ministério Público e as políticas públicas: definindo a agenda ou implementando as soluções?. Revista da AJURIS, Porto Alegre, v. 40, n. 130, p. 373-394, jun. 2013.

61 SILVA, Cátia Aida. Promotores de justiça e novas formas de atuação em defesa de interesses sociais e coletivos. Revista Brasileira de Ciências Sociais, São Paulo, v. 16, n. 45, p. 127-144, fev. 2001.
} 
institucional, o cidadão pode acessar todas as informações e serviços que o MPRN oferece e acompanhar a atuação institucional no combate ao coronavírus.

Entre as soluções inovadoras desenvolvidas para o enfrentamento da pandemia, também merece ser mencionado o aplicativo “Tô de Olho", desenvolvido pelo MPRN em parceria com o Instituto Metrópole Digital, da Universidade Federal do Rio Grande do Norte. A ferramenta traz informações sobre o quadro geral da pandemia no estado e pretende fazer um mapeamento das áreas de risco. Além disso, pela plataforma, qualquer cidadão pode mandar denúncias relativas ao descumprimento das normas de segurança à saúde para que sejam tomadas providências juntamente aos órgãos competentes.

Sugere-se, portanto, a ideia do Ministério Público do Estado do Rio Grande do Norte enquanto importante órgão de mediação na perspectiva de Da Ros ${ }^{62}$. Conforme mencionado, para o referido autor, de forma geral, é possível perceber a atuação ministerial como “órgão tutelar”, "órgão protetor” ou “órgão de mediação". Diante da superação da perspectiva meramente tutelar, este age além da proteção dos interesses coletivos e difusos, atuando em diversos momentos como um mediador dos conflitos sociais, o que ficou evidenciado no caso do $\mathrm{RN}$ durante o período analisado, principalmente quando privilegiou ações extrajudiciais e atuou como articulador político para pensar em estratégias colaborativas junto às gestões estadual e municipal para o enfrentamento da crise.

Nesse sentido, com base no referencial teórico adotado para a análise dos dados obtidos, a discricionariedade presente na instituição foi fator preponderante para o perfil identificado: um MP resolutivo ${ }^{63}{ }^{64}$, com a atuação de promotores de fato ${ }^{65}$, caracterizando uma postura de mediação ${ }^{66}$. Contudo, essa mesma discricionariedade tem o condão de alterar a dinâmica institucional harmônica e de promover desigualdades a partir de condutas rígidas e desatentas ao cenário político e social.

\section{Considerações finais}

A CF 88 trouxe, de um lado, um longo catálogo de direitos fundamentais e, de outro, redefiniu a atuação do Ministério Público, consagrando-o como instituição de defesa da sociedade e com a incumbência de velar pela efetividade daqueles direitos. A partir disso, no cumprimento de suas atribuições, as atividades do MP podem impactar nas políticas públicas, seja agindo em juízo ou fora dele. Sendo assim, revelam-se determinantes as garantias constitucionais da autonomia funcional e administrativa para o exercício de suas funções, conferindo-lhe discricionariedade e independência aos poderes públicos.

Seja na apreciação das relações sociais, seja na mediação de conflitos e tensões entre atores públicos, a atuação da instituição no contexto crítico e excepcional da pandemia do novo coronavírus buscou a efetividade de direitos em meio a uma gestão de crise complexa, com multiplicidade de atores envolvidos e de instâncias de decisão. Nesse contexto, foram verificados diferentes modelos de atuação do MPRN no desempenho de suas atribuições, permitindo sua classificação com base nas perspectivas de diversos autores.

Os instrumentos para sua atividade extrajudicial permitiram aos seus membros a adoção de estratégias inovadoras para solução de demandas, prestigiando uma atuação desburocratizada e voltada para a efeti-

\footnotetext{
${ }^{62}$ DA ROS, Luciano. Ministério público e sociedade civil no Brasil contemporâneo: em busca de um padrão de interação. Revista Política Hoje, Recife, v. 18, n. 1, 2009.

${ }^{63}$ GOULART, Marcelo Pedroso. Ministério Público e democracia: teoria e práxis. São Paulo: Led Editora de Direito, 1998.

${ }^{64}$ COELHO, Sérgio Reis; KOZICKI, Katya. O Ministério Público e as políticas públicas: definindo a agenda ou implementando as soluções?. Revista da AJURIS, Porto Alegre, v. 40, n. 130, p. 373-394, jun. 2013.

65 SILVA, Cátia Aida. Promotores de justiça e novas formas de atuação em defesa de interesses sociais e coletivos. Revista Brasileira de Ciências Sociais, São Paulo, v. 16, n. 45, p. 127-144, fev. 2001.

${ }^{66}$ DA ROS, Luciano. Ministério público e sociedade civil no Brasil contemporâneo: em busca de um padrão de interação. Revista Política Hoje, Recife, v. 18, n. 1, 2009.
} 
vação dos direitos fundamentais, mesmo diante da complexidade inerente às políticas públicas em cenário pandêmico no Rio Grande do Norte. Atuando em várias etapas e áreas de políticas públicas, em colaboração com diferentes esferas de governo, o MPRN buscou assegurar os direitos coletivos, demonstrando capacidade de exercer suas atribuições de maneira efetiva, resguardando ao gestor público a responsabilidade de decisão.

Vale ressaltar que os resultados apresentados reforçaram estudos ${ }^{67}$ sobre a discricionariedade que rege a atuação da instituição, indicando que tal característica pode se refletir em uma maior ou menor aproximação com o contexto de atuação, bem como com a possibilidade de geração de desigualdades.

Considerando-se continuidade do cenário de crise pesquisado, é fundamental o prosseguimento da investigação acerca do perfil de atuação do MPRN durante a crise da COVID-19, em relação à perspectiva de que surjam novas contribuições acerca do estudo da discricionariedade dentro da instituição. Além disso, sugere-se que novas análises possam ser realizadas no âmbito de outros estados, com o intuito de compreender se há uma padronização na atuação do Ministério Público a nível nacional.

\section{Referências}

ABREU, Alzira Alves de. O que é o Ministério Público? Rio de Janeiro: FGV, 2010.

ALMEIDA, Lindijane de Souza Bento et al. As universidades públicas brasileiras no contexto da pandemia: iniciativas e parcerias no enfrentamento da covid-19. Cadernos Gestão Pública e Cidadania, São Paulo, v. 25, n. 82, p. 82-100, set./dez. 2020.

ARANTES, Rogério Bastos. Ministério Público e Política no Brasil. São Paulo: Educ, Sumaré, Fapesp, 2002.

ARANTES, Rogério Bastos. Ministério Público na fronteira entre a justiça e a política. Revista Justitia, São Paulo, v. 1, n. 197, p. 325-335, jul./dez. 2007.

BRASIL. [Constituição (1988)]. Constituição da República Federativa do Brasil. Disponível em: http://www.planalto.gov.br/ccivil_03/constituicao/constituicao.htm Acesso em: 27 jan. 2021.

BRASIL. Conselho Nacional do Ministério Público. Recomendação Conjunta PRESI-CN nº 02, de 18 de junho de 2020. Disponível em: https://www.cnmp.mp.br/portal/atos-e-normas-separador/atos-e-normas-resultados Acesso em: 27 jan. 2021.

CECI, Mariana. Leitos gerais públicos de UTI estão lotados em Natal, diz SESAP. 2020. Disponível em: http:// www.tribunadonorte.com.br/noticia/leitos-gerais-paoblicos-de-uti-esta-o-lotados-em-natal-afirma-sesap-rn/479618 Acesso em: 11 fev. 2021.

COELHO, Sérgio Reis; KOZICKI, Katya. O Ministério Público e as políticas públicas: definindo a agenda ou implementando as soluções?. Revista da AJURIS, Porto Alegre, v. 40, n. 130, p. 373-394, jun. 2013.

DA ROS, Luciano. Ministério público e sociedade civil no Brasil contemporâneo: em busca de um padrão de interação. Revista Política Hoje, Recife, v. 18, n. 1, 2009.

FREY, Klaus. Políticas públicas: um debate conceitual e reflexões referentes à prática da análise de políticas públicas no Brasil. Revista Planejamento e Políticas Públicas, Brasília, n. 21, p. 211-259, jun. 2000.

\footnotetext{
${ }^{67}$ OLIVEIRA, Vanessa Elias de; LOTTA, Gabriela; VASCONCELOS, Natália Pires de. Ministério Público, autonomia funcional e discricionariedade: ampla atuação em políticas públicas, baixa accountability. Revista de Estudos Empíricos em Direito, São Paulo, v. 7, n. 1, p. 181-195, abr. 2020.
} 
GOMES, Luiz Henrique. Em cinco meses, covid matou mais que a violência no RN. Tribuna do Norte, 2020. Disponível em: http://www.tribunadonorte.com.br/noticia/em-cinco-meses-covid-matou-mais-que-a-viola-ncia-no-rn/487192. Acesso em: 11 fev. 2021.

GORDILHO, Heron José de Santana; SILVA, Marco Antonio Chaves da. Avaliando o novo Ministério Público Resolutivo. Revista de Processo, Jurisdição e Efetividade da Justiça, Porto Alegre, v. 4, n. 2, p. 85-99, jul./ dez. 2018.

GOULART, Marcelo Pedroso. Ministério Público e democracia: teoria e práxis. São Paulo: Led Editora de Direito, 1998.

MACIEL, Débora Alves; KOERNER, Andrei. Sentidos da judicialização da política: duas análises. Lua Nova, São Paulo, n. 57, p. 113-133, 2002.

MAZZILLI, Hugo Nigro. O acesso à Justiça e o Ministério Público. 1989. Disponível em: http://mazzilli.com. br/pages/artigos/acjusmp.pdf. Acesso em: 05 mar. 2021.

MP-RN desautoriza promotor e pede desistência de ação que analisa toque de recolher. Jurinews, 2021. Disponível em: https://jurinews.com.br/fogo-no-parquinho/mp-rn-desautoriza-promotor-e-pede-desistencia-do-ms-que-analisa-toque-de-recolher/ Acesso em: 12 mar. 2021.

NASCIMENTO JUNIOR, José Dias do. RN tem pico de infecção sem precedentes e contabilizados na semana de 15 de outubro de 2020. 2020. Disponível em: https://jd-donascimento.medium.com/rn-tem-pico-de-contamina \%C3\%A7\%C3\%A3o-sem-precedentes-na-semana-de-15-de-outubro-cd9651dd05c5 Acesso em: 10 fev. 2021.

OLIVEIRA, Vanessa Elias de; LOTTA, Gabriela; VASCONCELOS, Natália Pires de. Ministério Público, autonomia funcional e discricionariedade: ampla atuação em políticas públicas, baixa accountability. Revista de Estudos Empiricos em Direito, São Paulo, v. 7, n. 1, p. 181-195, abr. 2020.

RIO GRANDE DO NORTE. Secretaria de Estado de Saúde Pública. Informe Epidemiológico Coronavírus (Covid-19) $n^{0}$ 101, 01/07/2020. Disponível em: http://www.adcon.rn.gov.br/ACERVO/sesap/DOC/ DOC000000000234435.PDF Acesso em: 10 fev. 2021.

RIO GRANDE DO NORTE. Secretaria de Estado de Saúde Pública. Informe Epidemiológico Coronavírus (Covid-19) $n^{0}$ 137, 12/08/2020. Disponível em: http://www.adcon.rn.gov.br/ACERVO/sesap/DOC/ DOC000000000237557.PDF Acesso em: 10 fev. 2021.

RIO GRANDE DO NORTE. Tribunal de Justiça do Estado do Rio Grande do Norte (Tribunal Pleno). Pedido de desistência em Mandado de Segurança Cível ño 0800094-47.2021.8.20.5400. Relator: Des. Dirlemando Mota, 09 de março de 2021. Disponível em: https://jurinews.com.br/wp-content/uploads/2021/03/Pedido-do-PGJ-de-desist\%C3\%AAncia-do-MS.pdf Acesso em: 12 mar. 2021.

RIO GRANDE DO NORTE. Tribunal de Justiça do Estado do Rio Grande do Norte. Decisão monocrática em Mandado de Segurança Cível no 0800094-47.2021.8.20.5400. Relator: Des. Dirlemando Mota, 12 de março de 2021. Disponível em: https://jurinews.com.br/wp-content/uploads/2021/03/DECIS\%C3\%83O-MS-coletivo-ilegitimidade-ativa-PmJ-homologa-desist\%C3\%AAncia-PGJ.pdf Acesso em: 12 mar. 2021.

SILVA, Cátia Aida. Promotores de justiça e novas formas de atuação em defesa de interesses sociais e coletivos. Revista Brasileira de Ciências Sociais, São Paulo, v. 16, n. 45, p. 127-144, fev. 2001.

SILVEIRA, Raquel Maria da Costa et al. Governança metropolitana em tempos de pandemia. In: CLEMENTINO, Maria do Livramento; ALMEIDA, Lindijane; SILVA, Brunno (orgs.). Em tempos de pandemia: contribuições do Observatório das Metrópoles: núcleo Natal. Rio de Janeiro: Letra Capital, 2020.

VALENTIM, Ricardo et al. (org.). Rio Grande do Norte: uma análise da epidemia da covid-19: análise da evolução da epidemia da covid-19 no estado do RN à luz da ciência de dados na saúde. 2020. Disponível 
em: https://covid.lais.ufrn.br/publicacoes/Relatorio_covid-19-LAIS_UFRN_20201219.pdf Acesso em: 24 fev. 2021.

VIANNA, Luiz Werneck (org.). A democracia e os três poderes no Brasil. Belo Horizonte: UFMG, 2002. 
Para publicar na revista Brasileira de Políticas Públicas, acesse o endereço eletrônico www.rbpp.uniceub.br

Observe as normas de publicação, para facilitar e agilizar o trabalho de edição. 